2011-08-11

\title{
Implications of Dune Pattern Analysis for Titan's Surface History
}

Christopher Jon Savage

Brigham Young University - Provo

Follow this and additional works at: https://scholarsarchive.byu.edu/etd

Part of the Geology Commons

\section{BYU ScholarsArchive Citation}

Savage, Christopher Jon, "Implications of Dune Pattern Analysis for Titan's Surface History" (2011). Theses and Dissertations. 3077.

https://scholarsarchive.byu.edu/etd/3077

This Thesis is brought to you for free and open access by BYU ScholarsArchive. It has been accepted for inclusion in Theses and Dissertations by an authorized administrator of BYU ScholarsArchive. For more information, please contact scholarsarchive@byu.edu, ellen_amatangelo@byu.edu. 
Implications of Dune Pattern Analysis for Titan's Surface History

\title{
Christopher Jon Savage
}

\begin{abstract}
A thesis submitted to the faculty of
Brigham Young University

in partial fulfillment of the requirements for the degree of
\end{abstract}

Master of Science

Jani Radebaugh, Chair

Eric Christiansen

Thomas Morris

Department of Geological Sciences

Brigham Young University

December 2011

Copyright (C 2011 Christopher Jon Savage

All Rights Reserved 


\author{
ABSTRACT \\ Implications of Dune Pattern Analysis for Titan's Surface History \\ Christopher Jon Savage \\ Department of Geological Sciences, BYU \\ Master of Science
}

Analyzing dune parameters such as dune width and spacing can be useful in determining the reaction of dunes to changes in atmospheric and sedimentary conditions currently and in the recent geologic past. Dune parameters, dune width and spacing, were measured for linear dunes in regions across Saturn's moon Titan from images T21, 23, 28, 44 and 48 collected by Synthetic Aperture RADAR aboard the Cassini spacecraft in order to reconstruct the surface history of Titan. Dunes in the five study swaths are all linear in form, but lack superimposed or flanking dunes. They have a mean width of $1.3 \mathrm{~km}$ and mean crest spacing of $2.7 \mathrm{~km}$, wider and farther apart on average than similar terrestrial dunes in the Namib and Agneitir Sand Seas though larger linear dunes exist on Earth. Because of the lack of superimposed and flanking dunes and their size, Titan's dunes are classified as very large simple linear dunes. The large size, spacing and uniform morphology are all indicators that Titan's dunes are very mature and long-lived features. The ratio of dune width to spacing for Titan's dunes is similar to that found in terrestrial dunes in that dune spacing tends to be twice dune width. In addition to being similar in size, this is further evidence that terrestrial dunes can be used as analogues for Titan's dunes and vice versa and that the essential dune-forming processes are the same on both bodies. Dune width and spacing decrease northward, which is attributed to, but not limited to, increased maturity of dune fields to the south or increased sediment stabilization to the north. Sediment stabilization may be caused by Titan's asymmetric seasons and a net transport of moisture from south to north. The majority of dunes have spacings consistent with an upper limit of 2 to $4 \mathrm{~km}$ established by the atmospheric boundary layer, further evidence they are mature. Dunes are more widely spaced in the south are evidence they have been growing toward a steady state for a longer period of time than those in the north. Titan's large linear dunes have long reconstitution times. This is in part due to the fact that winds sufficient for saltation are reached only near the Titan equinox every 14 Earth years. Based on rates for similar terrestrial dunes the reconstitution time for Titan's dune is 600,000 Earth years or more, and therefore substantial changes in dune form should not be observable over Cassini's lifetime. Cumulative probability plots of dune parameters measured at different locations across Titan indicate there is a single population of dunes on Titan. This suggests that, unlike analogous dunes in the Namib and Agneitir Sand Seas, dune-forming conditions that currently exist on Titan are either the only dune-friendly conditions in the moon's history, or the current conditions have been stable and active long enough to erase any evidence of past conditions.

Keywords: Titan, linear dunes, pattern analysis, Cassini, RADAR 


\section{Contents}

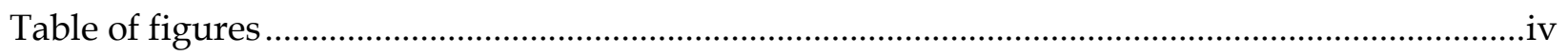

Table of tables

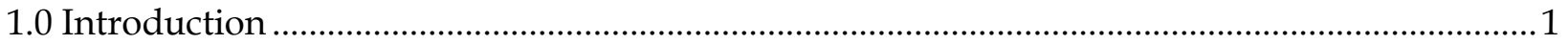

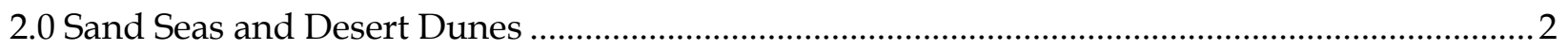

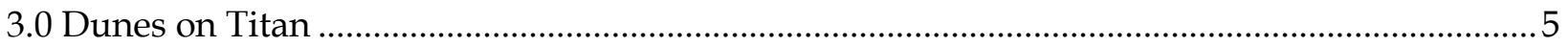

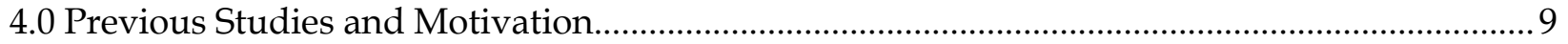

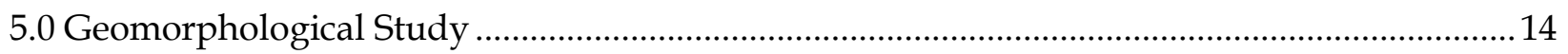

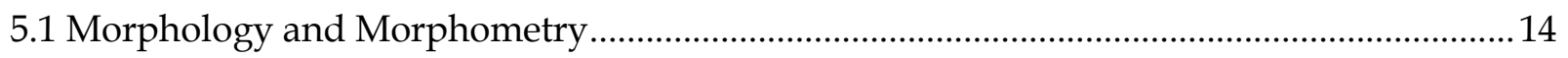

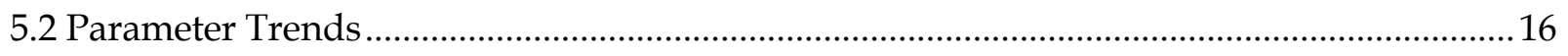

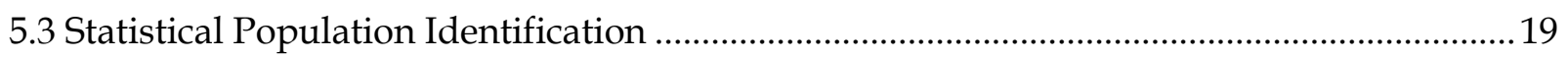

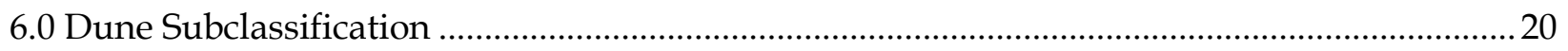

7.0 Controlling Factors of Dune Morphology and Size ..............................................................22

7.1 Linear Dune Maturity and Wind Regime Stability .............................................................. 22

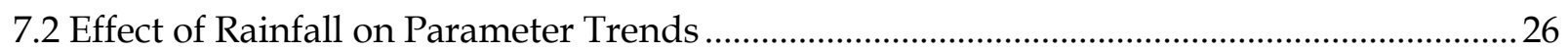

7.3 Effect of the Atmospheric Boundary Layer on Dune Parameters........................................30

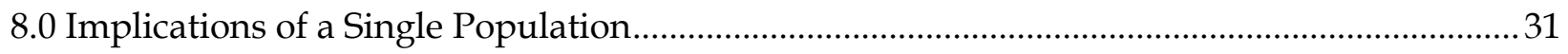

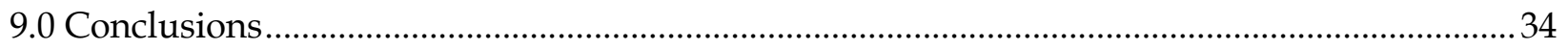

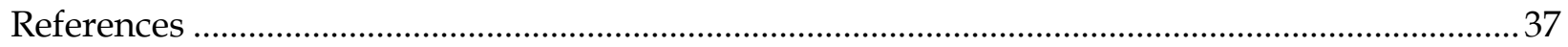

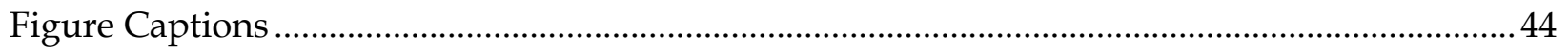

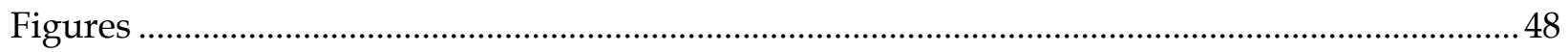

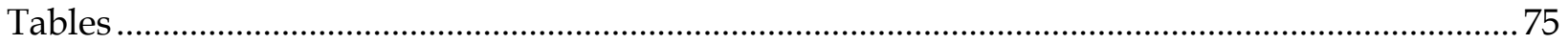




\section{Table of figures}

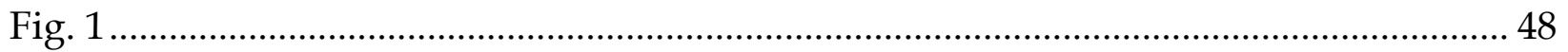

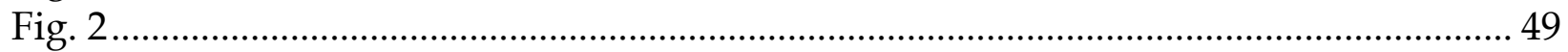

Fig. 3 .

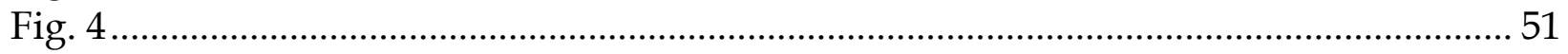

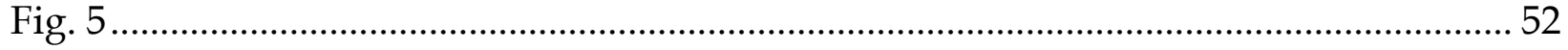

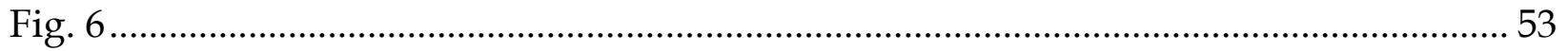

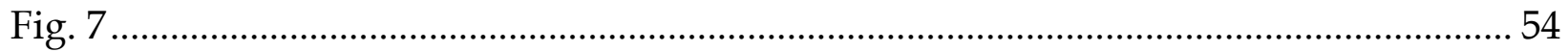

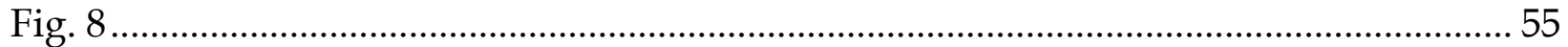

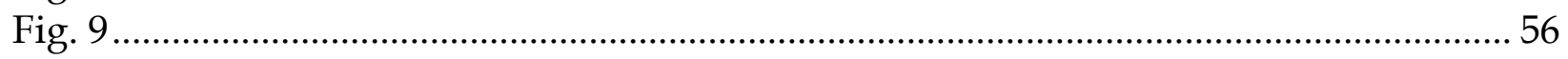

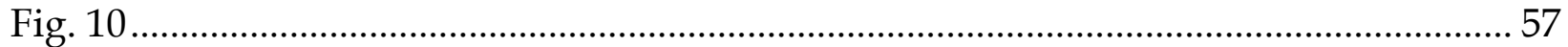

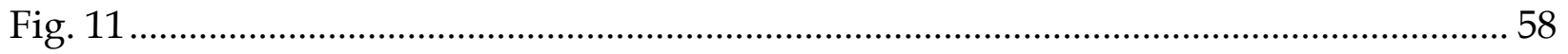

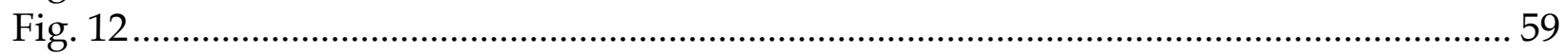

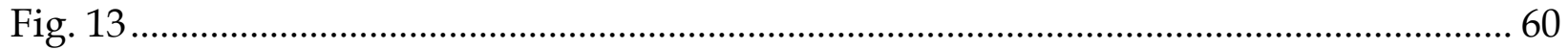

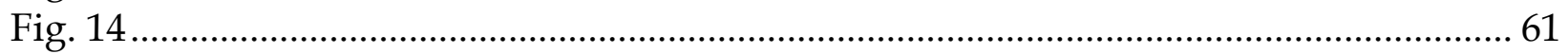

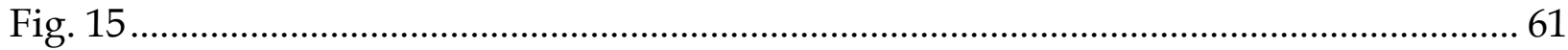

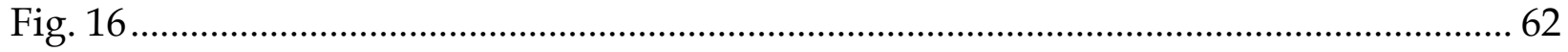

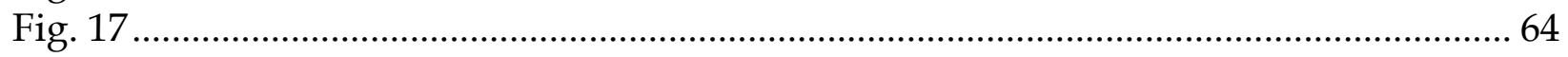

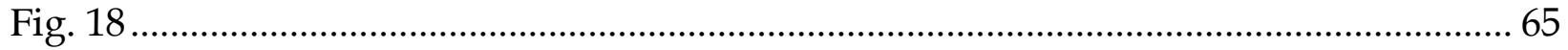

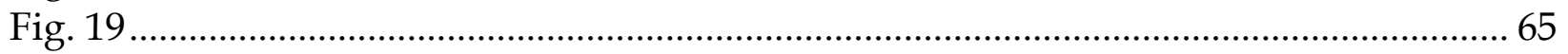

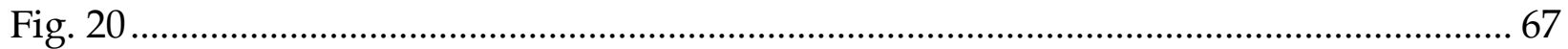

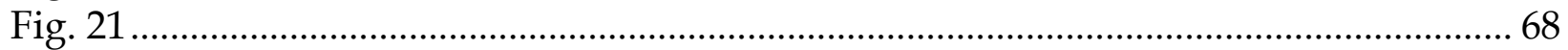

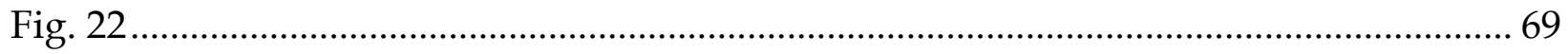

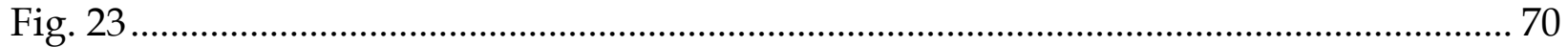

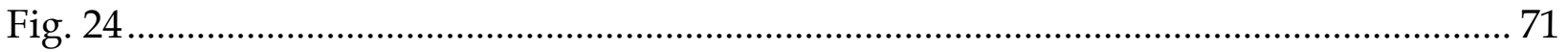

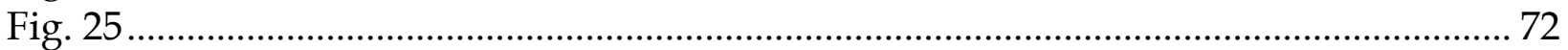

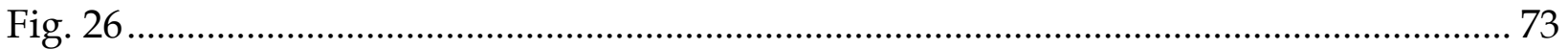

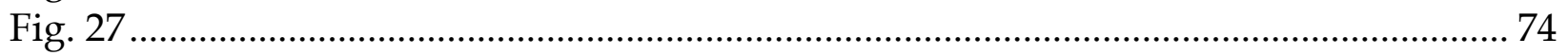




\section{Table of tables}

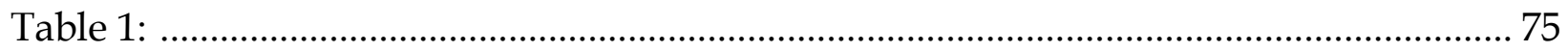

Table 2: 


\subsection{Introduction}

Linear dunes are the most abundant type of dune on Earth and Saturn's moon Titan (Bullard et al., 1995; Lorenz et al., 2006; Radebaugh et al., 2008). They form a major part of the sediment transport system, represent the results of major atmospheric and surface processes, and are sensitive to changes in both (Lancaster, 1995; Warren and Allison, 1998). Linear dunes account for nearly $40 \%$ of all terrestrial dune forms (Bullard et al., 1995), and cover at least $15 \%$ of the surface of Titan (Le Gall et al., 2011). Despite their abundance, however, the origin and evolution of linear dunes are poorly understood (Bullard et al., 1995; Stokes et al., 1997; Bristow et al., 2000; Munyikwa, 2005), especially for Titan, since in-situ data are virtually nonexistent. A detailed geomorphologic study of these features can reveal important relationships and processes and illuminate the evolutionary history of the surface. Titan is a unique and useful place for studying dunes on a large scale, since many dune fields stretch across several hundred to over a thousand kilometers and together span nearly the entire equatorial region, in many places reaching to $\pm 30^{\circ}$ latitude (Lorenz et al., 2006; Radebaugh et al., 2008; Le Gall et al., 2011).

An intriguing avenue of Titan research deals with the question of how Titan's dunes respond to variations in atmospheric and sedimentary conditions and if dune fields record any evidence for how those conditions have changed through time. Pattern analysis of dune parameters, such as crest spacing and 
dune width, has been shown to be a useful tool in answering such questions for dunes on Earth and Mars (Ewing et al., 2006; Ewing et al., 2010). When viewing dune-fields as two-dimensional objects, as with remote sensing images such as those collected from aerial photography or satellites, the measureable parameters of dunes are dune width and crest spacing, dune crest orientation, length and defect density (none of the last three are measured for this study). Statistical parameter analysis is a useful tool for determining the effects of populationrelated spatial variations in dune-forming conditions such as surface moisture and wind regime stability. The purpose of this study of Titan's linear dunes is to apply pattern analysis of dune field parameters, such as dune width and crest spacing, in order to (1) identify correlations that exist between dune field parameters and location, mainly latitudinal, on Titan and propose possible mechanisms for these trends; (2) identify the number of dune populations present on Titan; (3) relate these populations to the minimum number of duneforming events over the recent history of Titan; and (4) establish relative durations for these dune-forming events.

\subsection{Sand Seas and Desert Dunes}

Deserts are found on every continent on Earth. More than 95\% of Earth's quartz sand is contained within large areas $\left(>100 \mathrm{~km}^{2}\right)$ of wind-blown sediment called sand seas (Wilson, 1973). Major sand seas on Earth cover as much as $45 \%$ of all land area classified as arid (Lancaster, 1995). Additionally, sand seas and 
dune fields (large areas covered by dunes) have been identified on other bodies in our solar system including Venus (Greeley et al., 1992), Mars (Greeley and Iversen, 1985; Greeley et al., 1992; Edgett and Malin, 2000; Bishop et al., 2002) and Saturn's moon Titan (Lorenz et al., 2006; Radebaugh et al., 2008). Sand seas are host to a variety of features from sand sheets to yardangs to dunes (Ritter et al., 2002). There are several key criteria that need to be met in order for dunes to form on any planetary body, and these also play major roles in controlling the morphology, size and spacing of dunes. Requirements include an arid climate, supply of sand-sized sediments, winds strong enough to transport sand-sized sediments, a basin or sink in which sediments may collect, and a lack of trapping, in bodies of water for example, or removal mechanisms (Bagnold, 1941; McKee, 1979; Lancaster, 1989; Lancaster, 1995; Bourke et al., 2010). The thickness of the atmospheric boundary layer is also a factor that can control dune size and spacing by limiting dune height, which is related to dune spacing (Claudin and Andreotti, 2006; Lorenz et al., 2006; Andreotti et al., 2009).

Dune forms, ranging from large, complex linear dunes hundreds of meters in width and height to ripples smaller than a few centimeters, represent the intricate interactions between atmosphere and sediment (Lancaster, 1995; Warren and Allison, 1998; Claudin and Andreotti, 2006). Furthermore, dunes preserve within their various arrangements a record of changes in atmosphere/sediment interactions on time scales reflecting their sizes and thus stability or maturity. Ripples record changes over timescales of minutes to hours, 
crestlines often record seasonal variations and larger dune orientations represent stable wind regimes lasting up to thousands of years (Warren and Knot, 1983; Lancaster, 1995; Warren and Allison, 1998).

Dune types (Fig. 1) reflect wind direction variability and sediment availability. Types range from barchan dunes (simple, unidirectional wind flow and low sand supply), to star dunes (multidirectional wind flow and high sand supply) (Bishop et al., 2002). Linear dunes, the dune type of interest for this study, are the result of bimodal winds (Tsoar, 1983; Livingstone, 1989; Tsoar, 1989; Livingstone, 1993; Lancaster, 1995; Wang et al., 2004; Munyikwa, 2005; Reffet et al., 2010) or barchan elongation (Bagnold, 1941; Tsoar, 1984; Lancaster, 1995). Sediment supply can vary from moderate to voluminous and still produce linear dunes and form in a wide range of sediment availabilities, from moderate to voluminous (Lancaster, 1989; Lancaster, 1995; Bishop et al., 2002).

Linear dunes are straight or slightly sinuous sand ridges (Breed and Grow, 1979; Lancaster, 1995; Munyikwa, 2005) and come in three varieties based upon their crestlines and the presence or absence of superimposed flanking dunes: simple, compound and complex (Breed and Grow, 1979). Simple linear dunes (Fig. 2a) have single, straight or sinuous crestlines with no superimposed flanking dunes (Munyikwa, 2005). Compound linear dunes have 2 to 4 sinuous ridges that merge (Lancaster, 1995; Munyikwa, 2005). Complex linear dunes (Fig. $2 \mathrm{~b}$ and Fig. 3 ) are the largest (50 - $150 \mathrm{~m}$ high, $1-2 \mathrm{~km}$ spacing) with a main 
crestline and often with distinct dentate (star-form) peaks and flanking crescentic dunes (Breed and Grow, 1979; Lancaster, 1995; Munyikwa, 2005).

\section{Fig. 1, 2, 3}

3.0 Dunes on Titan

Titan was discovered in 1655 by Christiaan Huygens, an amateur Dutch astronomer, and has been the object of fascination for scientists and the public ever since (Coustenis et al., 2009). Titan is Saturn's largest moon and the second largest moon in the Solar System after Jupiter's Ganymede. Titan has long been known to be shrouded by a thick, opaque atmosphere (first observed by Jose Comas Sola in 1908 and confirmed by Gerald Kuiper in 1944) composed of large amounts (>90\%) of nitrogen and a smaller, yet significant, percentage of methane (1.5\%) (Kuiper, 1944; Lebreton et al., 2005; Lorenz, 2006; Coustenis et al., 2009). Observing the surface of Titan without special methods and instrumentation is difficult if not impossible (Kuiper, 1944; Coustenis et al., 2009). The CassiniHuygens mission was launched in 1997 to more fully explore the Saturnian system and especially Titan (Lebreton et al., 2005). The Cassini spacecraft was equipped with several effective ways to observe beneath Titan's thick atmosphere: the Huygens Probe and three orbited instruments. The Synthetic Aperture RADAR instrument is described in detail below. The spacecraft also carries with it the Visual and Infrared Mapping spectrometer (VIMS) and the 
Imaging Science Subsystem (ISS), both designed to collect images in the visible and infrared spectrums at specially selected wavelengths that allow for atmospheric penetration (Brown et al., 2005; Porco et al., 2005). The Huygens probe was designed to descend slowly through Titan's atmosphere, collect data on atmospheric composition and temperature, capture images during the descent, and study the composition of the surface (Lebreton and Matson, 2002; Matson et al., 2002; Lebreton et al., 2005). The probe revealed that the atmospheric haze, observed from Earth and by the Voyager 1 spacecraft (Smith et al., 1981; Smith et al., 1982; Coustenis et al., 2009), reaches all the way to the surface and that the temperature profile of the atmosphere much resembled Earth's although vertically extended (Lebreton et al., 2005; Lorenz, 2006).

Cassini's Ku-band $(13.8 \mathrm{GHz}, \lambda=2.17 \mathrm{~cm})$ Synthetic Aperture RADAR (SAR) (Elachi et al., 2005; Elachi et al., 2006) instrument is able to penetrate through the thick haze that shrouds Titan and collect images (Fig. 4) of the surface (Kuiper, 1944; Elachi et al., 1991; Elachi et al., 2004; Lorenz, 2006). The SAR mode is used under altitudes of $4,000 \mathrm{~km}$ producing images with spatial resolutions of $\sim 350 \mathrm{~m}$ to $>1 \mathrm{~km}$. A swath $120-450 \mathrm{~km}$ wide, covering around $2 \%$ of the surface, is created from 5 antenna beams as the spacecraft passes by Titan (Lopes et al., 2007). At the time of this study 36 RADAR swath images have been collected, covering close to $50 \%$ of Titan's surface (with overlap and several images below $2 \%$ coverage). However, not every swath crosses dune fields.

\section{Fig. 4}


The Cassini-Huygens mission has revealed Titan to be a world in many ways like Earth, with weather patterns and a surface with varied and complex geomorphology (Lorenz, 2006). The surface pressure is 1.5 bars with a temperature of only $94 \mathrm{~K}$ (Lebreton et al., 2005), which allows methane to be stable as a liquid, to rain out of the atmosphere, pool on the surface in lakes and flow in river channels (Hayes et al., 2008; Lorenz et al., 2008). Mountains are not uncommon (Radebaugh et al., 2007) and there are confirmed impact craters, though fewer than expected compared to other bodies in the solar system (Lorenz et al., 2007; Wood et al., 2010). The lack of craters indicates that Titan's surface is very young; between 100 and 500 million years old (Lorenz et al., 2007; Wood et al., 2010).

Photochemical reactions in Titan's atmosphere produce complex hydrocarbon and/or nitrile particulates that accumulate on the water ice-rich surface like black or brown snow (Soderblom et al., 2007). The hydrocarbon and/or nitrile particulates are dark to RADAR. This indicates they are smooth or absorbing at that RADAR wavelength $(2.17 \mathrm{~cm})$. They are also dark in the visible and near-infrared spectrum. The hydrocarbon and nitrile particles are deposited, then perhaps solidified into a sedimentary layer, then eroded by methane rainfall and surface flow into sand-sized particles. With Titan's low gravity and thick atmosphere the optimum particle size for saltation on Titan has been calculated to be $\sim 0.3 \mathrm{~mm}$. This calculation assumes that freestream wind speeds required 
for transportation are $>1 \mathrm{~m} / \mathrm{s}$. Near surface wind speeds were measured by the Huygens Lander to be between 0.2 and $0.3 \mathrm{~m} / \mathrm{s}$ for the short period of time the lander was operational (Lorenz et al., 2006; Lorenz, 2010). Eventually the particles are worked by near-surface winds into large fields of sand dunes (Lorenz et al., 2006; Barnes et al., 2008; Radebaugh et al., 2008). Dunes are abundant on Titan's surface, covering at least $15 \%$, and found within a belt $\pm 30^{\circ}$ latitude of the equator (Lorenz et al., 2006; Radebaugh et al., 2008; Le Gall et al., 2011). In this region, there are no large bodies of liquids and few topographic obstructions to disrupt global wind patterns or dune formation (Lorenz et al., 2006; Radebaugh et al., 2008; Radebaugh et al., 2010).

The vast majority of Titan's dunes are linear in form and oriented nearly parallel to the equator (Barnes et al., 2008; Lorenz and Radebaugh, 2009). They range in size from 1-2 $\mathrm{km}$ wide, $1-4 \mathrm{~km}$ spacing, up to $150 \mathrm{~m}$ high and can be more than $100 \mathrm{~km}$ long (Lancaster, 2006; Lorenz et al., 2006; Radebaugh et al., 2008). Titan's dunes are currently active, or at least were in the recent geological past. Evidence of this is that the interdune area in many of the dune fields is clearly distinguishable as a RADAR-light area from dune areas in both RADAR and VIMS, meaning that the substrate is exposed and kept clear of any dune sediments that may have blown or flowed, by mass wasting, into the interdune areas (Barnes et al., 2008). Inactive sand seas on Earth have continuous sand coverage across the interdune area because of these degradational processes. There are obvious differences in the conditions under which dunes form on 
Earth and Titan. Namely on Titan gravity is lower, the atmosphere is denser, the sand grain density is less and moisture is in the form of liquid methane rather than liquid water. Despite these differences the size, morphology, and behavior of Titan's dunes around obstacles are so similar to large linear dunes on Earth, processes attributed to forming terrestrial linear dunes are applied to dunes on Titan (Lorenz et al. 2006; Radebaugh et al. 2008; Radebaugh et al. 2010; LeGall et al. 2011).

4.0 Previous Studies and Motivation

The majority of the studies of Titan's linear dunes have focused on their morphology and associations with topographic obstacles (Lorenz, et al., 2006; Radebaugh et al., 2008; Barnes et al., 2008; Lorenz and Radebaugh, 2009; Radebaugh et al., 2010). Many studies of RADAR images that contain dune fields are concerned with the RADAR properties of the dune material and how they differ from surrounding areas (Paganelli et al., 2007; Paganelli et al., 2008; Janssen et al., 2009; Le Gall et al., 2011). Few studies have attempted to quantify the parameters of Titan's dunes (dune width, length, height and crest spacing), find correlations among these parameters or determine how they change as a function of their location (i.e. latitude) and none have done this on a large scale. Two exceptions are Lorenz and Radebaugh (2009) and LeGall et al. (2011). Lorenz and Radebaugh (2009) measured 16,000 dunes, documenting dune length and orientation to establish general near-surface wind direction based on 
dune orientations and their interactions with topographic obstacles. LeGall et al. (2011) examined dune fields in RADAR swaths up to T55 (May 15, 2009) noting in particular the RADAR emissivity and brightness of Titan's dunes and discovered a latitudinal dependence related to increasing interdune fraction (ratio of interdune area to dune width) with increasing latitude. Width and spacing measurements made for the current study were used to calculate the interdune fraction found in Le Gall et al. (2011). On a smaller scale, Lorenz et al., (2010) made several dune spacing measurements on four image swaths (T21, 25, 41, 41 HiSAR), with fewer than 10 measurements on each swath. Though limited, these measurements provide some support of the results presented in this study.

Ewing et al. (2006) performed an analysis of terrestrial dune-field parameters, which is easily applied to data obtained from remote sensing images of Titan's linear dune fields. The study done by Ewing et al. (2006) selected four dune fields from around the planet and obtained measurements for the dunefield parameters dune spacing and height. From these data were constructed cumulative probability plots much like those used in mineral exploration, reservoir characterization and grain-size distribution. The basis behind using such plots lies in a modification of the Central Limit Theorem (CLT) of statistics, which states that if the sample size is large enough, the distribution of sample means can be approximated by a normal distribution, even if the original population is not normally distributed (Triola, 2004). Thus, smaller populations of dunes can be identified if they exist within the larger population of the 
sampled dune field or sand sea. These smaller populations are distinct and display their own normal distributions.. The Ewing et al. (2006) study alters the CLT in several important ways. First, log-frequency replaces cumulative frequency. This means that the CLT applies to multiplicative rather than additive events. Their study also used the CLT in reverse, meaning that when a lognormal distribution is observed in a set of data, as much information as possible has already been extracted from the data without the presence of other data. In other words, one might erroneously conclude that a distribution is log-normal simply because the data set is not large enough (Ewing et al., 2006). For Titan this poses a problem in that not all dunes present on the surface at the scale of the study $(300 \mathrm{~m})$ have been included in the data set either because they have not yet been imaged by RADAR or have not yet been measured. The current study only includes dunes from five study swaths visible at Cassini image resolution of $\sim 350$ $\mathrm{m}$.

The Ewing et al. (2006) study applies statistical pattern analysis to four terrestrial dune fields, including two fields of linear dunes, in order to see if different populations of dunes exist within the same field. Identification is done by plotting data sets on cumulative probability plots. The population (e.g. an entire dune field), with an infinite number of potential data values, is represented by a line on a log-normal plot of cumulative probability that can be characterized by a single mean and standard deviation if the data are the result of a single mechanism or dune-building event (Fig. 5a). If the data are the result 
of multiple mechanisms, then multiple lines, each with its own mean and standard deviation will be present, separated by breaks or inflection points (Fig. $5 b)$. Each population represented on the plots represents a significant change in conditions, such as wind direction, sediment availability or sediment mobility, and can be identified and separated from other populations to further investigate the formative conditions at specific points in time where sediment dates are available. Otherwise formative conditions can only be evaluated at relative points in time. Cumulative probability plots made from dune spacing from the Namib (Fig. 6a) and Agneitir Sand Seas (Fig. 6b) show that each contains at least three populations of dunes as represented by distinctly sloping line segments separated by inflection points. Each of these plots depicts two significant shifts in dune-forming conditions and wind regime represented by an inflection point and thus the minimum number (i.e. three in the Namib and Agneitir Sand Seas of dune forming periods.

\section{Fig. 5, 6}

After identifying populations, Ewing et al. (2006) show it is possible to perform geomorphic backstripping, wherein generations of dunes are progressively unstacked to reveal the evolution of a complex dune-field pattern over time. Each generation is then available for reconstruction of conditions that gave rise to it and the construction times required to form it. To strengthen their study they provide ranges of formation time with Optically Stimulated Luminescence (OSL) data of sands obtained from key locations within the dune 
region. OSL dates for key regions within two of the Ewing et al. (2006) dune study areas, the Namib and Agneitir (Mauritania), corroborate 3 separate duneforming events for dunes in each sand sea.

While such dating methods as OSL are not available for Titan's dunes, both the identification of populations and estimation of the minimum number of events or significant changes in dune-forming conditions are possible using pattern analysis as described above resulting in the reconstruction of dune field evolution. It is yet unclear how much information this method can provide for Titan since Cassini RADAR image resolution is $\sim 350 \mathrm{~m}$, about half the width of the smallest resolvable large linear dunes. Each pixel in the SAR images is about $175 \mathrm{~m}$ across, and although linear features with high radar contrast, such as dunes, can be detected at this size or smaller, it is not possible to tell if the dune is actually slightly larger or slightly smaller than $175 \mathrm{~m}$. This is significant because Titan's dunes could host superimposed or flanking dunes, if they are similar to those on Earth. Many of the flanking dunes in the Namib and Agneitir Sand Seas are more than 175 m apart (Breed and Grow, 1979; Lancaster, 1989; Lancaster, 1995; Ewing et al., 2006) and would be apparent with Cassini SAR imagery. 
5.0 Geomorphological Study

\subsection{Morphology and Morphometry}

Titan's dune widths and crest spacings (Fig. 7) were measured in five RADAR (SAR) swath images, T21, 23, 28, 44, and 48 (see Fig. 4 for locations), collected by Cassini's Ku-band, 2.17 cm RADAR instrument. These swaths were chosen because they contain many dunes and cover a large range of latitudes. The images were loaded in ISIS, a United States Geological Survey imageprocessing program. Measurements were made at regular $5 \mathrm{~km}$ intervals along dune axes in order to obtain enough measurements along a single dune axis to capture variations. Since most dunes on Titan are many times longer than $5 \mathrm{~km}$, this spacing should provide an adequate sampling to capture significant changes. Tests using smaller measurement intervals of 1.76 and $0.8 \mathrm{~km}$ did not yield significantly different results than the $5 \mathrm{~km}$ interval. Dune widths were measured perpendicular to the long axis and taken to be the width of the RADAR-dark streaks, which are interpreted as dunes (Fig. 8). Interdune spacing was obtained in similar fashion except the width of the RADAR-light areas between the dark streaks was measured. Since dune crests are not commonly visible in the RADAR images the crest-to-crest spacing, a common measurement in terrestrial dune analysis (Breed and Grow, 1979; Lancaster, 1989; Lancaster, 1995; Ewing et al., 2006) was approximated. This was accomplished by combining the interdune data sets for each swath into one large data set. Then the mean interdune spacing was taken for each degree latitude. That mean was 
then added to each individual width measurement per corresponding degree of latitude. This method was found to be at least as effective as measuring from the middle of one dune to the next (locations of dune middles had to be estimated), but the former method was utilized because crestlines are not possible to discern and because both dune and interdune widths were already available. In all, 14,050 individual dune width and crest spacing data points were collected.

\section{Fig. 7, 8}

The distribution of dune morphologies across the five study swaths appears to be homogeneous. All of the dunes observed and measured for this study are linear in form. Like many linear dunes on Earth those on Titan are generally slightly sinuous yet parallel (except at junctions) and have west-east orientations (Fig.9; Lorenz and Radebaugh 2009). Unlike terrestrial dunes of similar size, however, such as those found in the Namib Sand Sea in southern Africa, they do not appear to have smaller, superimposed flanking dunes. Or they may not be visible at Cassini RADAR image resolution. That the smaller dunes may not be present is supported by degraded RADAR images of terrestrial complex sand dunes in the Namib Sand seas near Tsondabvlei, Namibia to $350 \mathrm{~km}$ (175 m/ pixel) similar to Cassini RADAR images (figure 10 and 11). Much of the detail is lost in the degraded image; however, several important features are still visible. First, in areas of high contrast, light flanking dunes are visible against dark fields. Second, there is the main trend of large dunes visible clearly and then a set of smaller dunes oriented at a different angle 
in the lower right corner of the image, which could be interpreted as flanking or superimposed (the unaltered image shows they are not). Third, many of the shadows along single crestlines may be interpreted as separating multiple crestlines in the degraded image. It seems clear that not all of the small superimposed features are visible, many features smaller than the large dunes, near the $350 \mathrm{~m}$ resolution limit are visible in the terrestrial image. Similarly degraded RADAR images from the Sahara desert in Egypt support the lack of superimposed features on Titan (figure 12 and 13). These dunes show few if any flanking dunes and look strikingly similar to RADAR images of dunes fields found on Titan.

Titan's linear dunes are generally large, measuring from $0.4 \mathrm{~km}$ to about $3.6 \mathrm{~km}$ in width with a mean width of $1.3 \mathrm{~km}$ (figure 14, table 1). Dune spacing is also large ranging from $1.4 \mathrm{~km}$ to almost $5.3 \mathrm{~km}$ with a mean spacing of $2.7 \mathrm{~km}$ (figure 15, table 1). Dune width and crest spacing averages of each individual study swath are all within one standard deviation $(0.4 \mathrm{~km}$ and $0.5 \mathrm{~km}$ respectively) of the global Titan mean (1.33 km and $2.62 \mathrm{~km}$, respectively), and are larger on average than linear dunes in the Namib Sand Sea whose mean width is $0.9 \mathrm{~km}$ and mean spacing is $2.2 \mathrm{~km}$ (Lancaster, 1995).

\section{Fig. 9, 10, 11, 12, 13, 14, 15}

Table 1

\subsection{Parameter Trends}

Width and spacing for Titan's dunes vary with location. While dune width depends slightly on latitude, dune spacing does not seem to show such a 
trend (Fig. 16). The trend in dune width is visible in individual swaths (Fig. 17). This trend is also visible in dune spacing in some of the individual swaths (Fig. 18). Le Gall et al. (2011) were also able to establish a latitudinal dependence in the microwave electromagnetic signatures of the dune fields. The dune terrains are less emissive and brighter up to $11^{\circ} \mathrm{N}$ latitude, a factor that is likely controlled by the ratio of interdune width to dune width, called the interdune fraction. The interdune fraction trend is the inverse of the widths and spacings trends, in other words, the interdune fraction generally increases to the north.

\section{Fig. 16, 17, 18}

There are several exceptions to the trend of decreasing width with increasing latitude, many of which can be attributed to conditions within the field in which the dunes are located. For example, the dunes measured in swath T28 above $15^{\circ}$ latitude all reside in small, isolated fields (Fig. 19a). This also is the case for dunes in swath T23 between $-11^{\circ}$ and $-12^{\circ}$ latitude (Fig. 19b). In these smaller, isolated dune fields, dunes tend to be wider and more widely spaced than dunes found in larger dune fields such as those in T28 between $-7^{\circ}$ and $13^{\circ}$ (Fig. 20a) and those in swath T23 between $-3^{\circ}$ and $13^{\circ}$ (Fig. 20b). The dunes in large fields are more regularly spaced and have widths that decrease towards higher northern latitudes. Swath T44 contains outliers beyond this trend, but unlike those already mentioned the outlying dunes in T44 between $15^{\circ}$ and $19^{\circ}$ latitude are not members of small, isolated dune fields. In this region, it is difficult to accurately differentiate dunes from interdunes because both are dark. 
This could be for two reasons. One, the dark interdune areas are near the edges of the swath where resolution tapers off. Two, these areas have a high sediment supply and the interdune areas cannot be cleared of sediment. This could lead to less accurate measurements (Fig. 21). The region containing swath T21 and other areas, however, has a very high contrast between the interdune and dune (Fig. 22). The dunes in $\mathrm{T} 44$ between $15^{\circ}$ and $19^{\circ}$ latitude are also near the edge of the swath where resolution tends to degrade because Cassini is usually at higher altitudes when the edges of the swaths are imaged. Data from dunes in fields that did not seem as representative of most dunes on Titan, which occur in large dune fields were removed from correlation calculations. Including these data points decreases the $\mathrm{R}^{2}$ value for widths, and only slightly raises it for spacing (Fig. 23)

\section{Fig. 19, 20, 21, 22, 23}

Overall, dune spacing is more variable than dune width because of the variation of interdune widths. The high variability may be related to the sinuosity of the individual dunes especially where the dunes are not parallel. The same uncertainties that produce some of the error in dune width measurements, namely that there may be some subjectivity in where to call the actual border between light and dark, also affect the interdune width measurements. However, dune width measurements are not as affected by divergence of dune parallelism as are interdune widths so they tend to be more consistent and possibly more accurate. 


\subsection{Statistical Population Identification}

The utility of the cumulative probability plots (Ewing et al., 2006) is based on the principle that given a certain set of dune-forming conditions, a single population of dunes will form characterized by a unique set of parameters (i.e., dune width, spacing, etc.).

To construct the cumulative probability plots individual dune width and spacing measurements were ordered according to increasing size and assigned a number from 1 to $\mathrm{n}$. Cumulative probability was calculated by dividing the observation number by the total number of observations plus 1 . Since we are using frequency as an estimate of probability, a theoretical value is assigned to each probability. This theoretical value represents a value, $x$, such that there is a certain probability of occurrence based on a normal distribution. The graph is obtained by plotting the log of the parameter value (e.g. spacing or width) as a function of the theoretical $x$ value and then re-labeling the $x$-axis as cumulative probability.

Cumulative probability plots of dune widths and spacing (Fig. 24a and b) from dunes measured across all five study swaths on Titan suggest the dunes measured are from a single population. These plots show that there is a wide range in the values for each parameter representing a continuum of widths and spacings from the smallest to largest. This is true across Titan. Single populations are also seen in plots of each individual swath (Figs 25 and 26) with the possible exception of T23 in dune spacing. 


\section{Fig. 24, 25, 26}

\subsection{Dune Subclassification}

It is difficult to classify Titan's linear dune forms into simple, compound or complex since crestlines are not commonly visible. Having width and spacing measurements can assist in making loose form classifications. A proxy for linear dune type (simple, compound, complex) may exist in the ratio of dune width to crest spacing. Breed and Grow (1979) note that there appears to be a linear arithmetic relationship between mean widths and spacings across all linear dune types. This trend is particularly obvious for data taken from linear dune fields on Earth (see Table 2 for locations) with a correlation coefficient $\mathrm{R}^{2}=0.90$. The relationship between widths and spacings of all dunes measured per degree latitude on Titan also forms a linear trend, although the correlation (Fig. 27) is not as good, $R^{2}=0.35$. Both sets of data together, for Earth and Titan, have a correlation $\mathrm{R}^{2}=0.78$. Breed and Grow (1979) also showed that spacing tends to be about twice the mean width of linear dunes regardless of size (table 2), and this relationship indicates a progression of dune form, from simple to compound to complex, with increasing size. This trend is also found in Titan's dunes. Dune size may be used loosely as a proxy for dune form since increasing dune size on Earth seems to be associated with the development of subsidiary dunes, which may have slipfaces of the same or different orientations than the slipfaces of the main dune (Breed and Grow, 1979). Additionally, the continuity of the width and 
spacing ratio between terrestrial and Titanian dunes is further evidence that terrestrial dunes can be used as analogues for understanding Titan's dunes and that even though they are separated by nearly 800 million miles and made of different materials, the essential dune-forming processes are the same.

\section{Fig. 27}

\section{Table 2}

Titan's dunes are similar in dune width and spacing to terrestrial complex linear dunes (Fig. 26). If terrestrial dunes can be used as analogues, and the similar sizes are evidence that they can be, Titan's dunes should host smaller superimposed or flanking dunes. Such features have not been observed. This is either because they are smaller than the RADAR resolution or because they are not there. The smaller flanking and superimposed dune forms are necessary to classify a linear dune as compound or complex (Breed and Grow, 1979; Bourke et al., 2010). Terrestrial dunes of comparable size to Titan's dunes in the Namib Sand Sea and Agneitir Sand Sea nearly all have superimposed dunes large enough and sufficiently spaced to be visible, or at least detectable, at the best Cassini RADAR image resolution ( $\sim 350 \mathrm{~m})$, but no such dunes are observed in the five study swaths for this study. If this is a reality and not just a consequence of insufficient image resolution, the classification of Titan's dunes is that they are the size of complex linear dunes, but their morphology suggests that they are extremely large, simple linear dunes, and would thus be a departure from dune 
morphology of large linear dunes like those in the Namib Sand Sea (Bristow et al., 2007), which do host flanking and superimposed features.

7.0 Controlling Factors of Dune Morphology and Size

Controlling factors of dune size and morphology are complex but they include sediment supply, sediment mobility, wind direction variability and duration, and atmospheric boundary layer thickness (Bagnold, 1941; Lancaster, 1988; Warren and Allison, 1998; Claudin and Andreotti, 2006; Andreotti et al., 2009; Bourke et al., 2010; Lorenz et al., 2010; Le Gall et al., 2011). The overall dune width and spacing of Titan's dunes along with the decrease in dune width and spacing with increasing northern latitude may have their roots in any combination of these factors, which are discussed below.

\subsection{Linear Dune Maturity and Wind Regime Stability}

Dune size and morphological variety in a broad sense are largely

functions of dune-field maturity (Warren and Allison, 1998; Ewing et al., 2006). Maturity is thought to be a result of the length of time a dune field is exposed to a given set of formative conditions. Maturity is expressed by increasing dune similarity (uniform morphology), increased complexity, increased size and crest spacing, and decreased defect density, which is not measured for this study (Kocurek and Ewing, 2005; Ewing et al., 2006). Starting from any number of initial conditions or dune forms, holding wind regimes steady forces sand into dunes that evolve through smaller, less complex morphological stages until they 
reach the largest, most complex and best ordered form allowed by their environment (Breed and Grow, 1979; Hersen et al., 2002; Ewing et al., 2006; Andreotti et al., 2009; Kocurek et al., 2010; Lorenz et al., 2010). Thus, dune morphology, size and spacing are all indicators of relative dune field maturity. Small dunes form in short periods under consistent winds, while large dunes testify to longer periods of time with consistent winds (Warren and Allison, 1998). Ripples, for example, do not get very large, in part because the winds that form them are not consistent for very long. Ripples build and realign over a matter of minutes. Dune crests require longer-term, seasonal variations to realign and larger dune forms, such as the complex linear dunes in the Namib Sand Sea, are the result of long exposure to consistent wind regimes (Warren and Allison, 1998). Inconsistent wind patterns eventually destroy and reconstitute dunes (Warren and Allison, 1998). Thus, large dunes can be interpreted as being older or at least having been present in the wind regime under which they grew for a longer period of time than smaller dunes (Warren and Allison, 1998; Bristow et al., 2007).

The length of time that a dune needs to realign or reestablish this equilibrium is called reconstitution time (Warren and Allison, 1998). Dunes will seek the new equilibrium by either completely realigning themselves to be parallel to the mean wind direction or by forming superimposed dunes, a process that tends to be faster than complete realignment (Ewing et al., 2006). Computer simulations (Werner, 1995) and observations of wind ripples show 
that crest line reorientation begins at crest terminations. Reorientation of the crest is then translated through the dune form until the entire dune is in line with the new wind regime. Thus, the rate of dune reorientation is proportional to defect density, or the amount of crest terminations per unit length of crest line (Werner and Kocurek, 1997; Werner and Kocurek, 1999; Kocurek and Ewing, 2005). This in part explains the long-term morphological stability of linear dunes, which have the lowest defect densities of all common dunes (Werner and Kocurek, 1997). The reorientation rate or reconstitution time is also dependent on the sand volume being transported, meaning the larger the dune, the longer it will take to reorient (Warren and Allison, 1998; Kocurek and Ewing, 2005). What Warren and Allison (1998) call mega-dunes (dunes in equilibrium with annual wind regimes and larger than 3 - 5 meters high) have reconstitution times ranging from 7,000 years in the Wahiba Sands of Oman to 42,000 years in the Namib Sand Sea (Lancaster, 1988; Warren and Allison, 1998). These figures were calculated with the assumption that wind and sand transportation rates have remained at their current levels for thousands of years.

Superposition of new dunes upon older dunes is a much faster process that realignment and large linear dunes are often covered with several sets of superimposed or flanking dunes as a result. These are useful in reconstructing the history of dune fields. Multiple sets of superimposed dunes can be taken as an indication of the number of constructional episodes or, more specifically, significant changes in wind regime accompanied by an influx of sand either from 
new sources, sand blown from existing dunes or the partial reworking of existing dunes (Kocurek and Ewing, 2005; Ewing et al., 2006). Identification of different sets of superimposed or flanking dunes can be used in geomorphic backstripping, in which generations of dunes are progressively unstacked to reveal the evolution of complex dune-forming conditions at specific points in time (Ewing et al., 2006). The large linear dunes of the Namib Sand Sea, for example, are composed of the main linear dune with two sets of smaller, superimposed dunes, together representing at least three different periods of construction. Similarly, the dune fields of the Agneitir Sand Sea in Mauritania are comprised of three sets of linear dunes of different sizes and orientations, also representing at least three episodes of dune construction (Lancaster et al., 2002; Ewing et al., 2006). If Titan's dunes have not seen significant changes in wind regime in the geologically recent past, then geomorphic backstripping is a straightforward process. Without shifting winds, no superimposed or flanking dunes are created and all that is recorded in Titan's dunes is a single episode of building (see section 8.0 for more on this). Just how long that episode has lasted is another question altogether, not easily decipherable using geomorphic backstripping alone.

It is challenging to obtain an actual age of Titan's dunes; samples cannot currently be collected and direct measurements are not possible beyond what the Huygens Probe has already made. The ages we obtain are thus relative ages, with absolute age estimates from comparisons to terrestrial analogues. As 
mentioned, the reconstitution time for large linear dunes on Earth can range from $7 \mathrm{k}$ years, as in the Wahiba sands of Oman, to $42 \mathrm{k}$ years, as in the Namib Sand Sea (Warren and Allison, 1998). Titan's dunes are on average larger than these dunes by up to $400 \mathrm{~m}$ in width and more widely spaced by up to the same amount. If size and spacing are both good indicators of the maturity and relative age of a dune field, then the dunes on Titan would be older and more mature on average than the Namib dunes if they had formed under similar conditions. Additionally, there is evidence that the construction time for Titan's dunes would be at least 14 times longer than their terrestrial analogues (see next section) if they grew under the same conditions, though perhaps not uniformly across the moon.

The trend of decreasing width with latitude is at least in part explained by the maturity of the dunes. Since southern dunes are larger and more widely spaced than their northern counterparts, it may be that the southern dunes have been evolving for a longer period of time under dune-favorable conditions. Those conditions may have begun as a more narrow belt around the latitudes just south of the equator and have gradually expanded and moved north over time so that the northern dunes are still evolving to their limiting sizes. Similar conclusions were reached by Le Gall et al. (2011).

\subsection{Effect of Rainfall on Parameter Trends}

Dune size and spacing are also related to the amount of available sediment (Lancaster, 1989; Lancaster, 1995; Le Gall et al., 2011). Sediment may be 
trapped by vegetation or by moisture in the form of a high water table or surface covering. Since sediment stabilization by vegetation is not an issue on Titan, moisture is the more likely mechanism for stabilization. Reducing sand mobility on dunes would effectively reduce sediment supply and subsequently reduce their size (Kocurek, 1999). This is observed on Earth where dune fields encounter water tables related to sea level and where water table fluctuations occur within a basin as in White Sands, New Mexico and Padre Island, Texas (Kocurek et al., 2001; Le Gall et al., 2011), or where sediment is immobilized on the surface by fluids (Kerr and Nigra, 1952). On Titan liquid methane plays the role that liquid water does here on Earth in stabilizing sediments.

It is evident that Titan's seasonal cycles play an important role in dune formation. The composition of Titan's atmosphere (95\% Nitrogen, 4.9\% CH4;) and temperatures $(90.6 \mathrm{~K})$ are such that liquid methane is stable at the surface and up to $15 \mathrm{~km}$ vertically where liquid methane-nitrogen clouds form and produce what has been described as a methane drizzle that reaches the surface (Lebreton et al., 2005; Lorenz, 2006; Tokano et al., 2006). In some places the precipitation rate is around $50 \mathrm{~mm}$ yr-1 (Tokano et al., 2006) and though this precipitation rate may not have high erosion potential it is enough to wet materials and pool on the surface creating both rivers and lakes (Hayes et al., 2008; Lorenz et al., 2008).

Titan's North Polar Region is dotted with many such lakes filled with liquid methane (Stofan et al., 2007). Most lakes are located north of $55^{\circ}$ and cover 
slightly more than $10 \%$ of the surface there. Despite the fact that RADAR coverage at similar latitudes in the South Polar Region is greater $(60 \%$ as opposed to $50 \%$ ), filled lakes cover only $0.4 \%$ of the surface (Aharonson et al., 2009).

The asymmetry in the distribution of lakes has several important implications. First, it means that the seasons are not the same length in each hemisphere. Based on the eccentricity of Saturn's orbit around the sun, southern summers should be shorter but more intense. Solar insolation is about $24 \%$ greater, which leads to an enhancement in insolation-driven evaporation and precipitation: In short, there is a net transport of moisture from the south to the north (Aharonson et al., 2009). This asymmetry in moisture transportation is a possible explanation for the trend of decreasing dune width and spacing with latitude. Sediments further north remain wetted for longer periods of time, reducing their mobility and effectively restricting sediment supply and, consequently, dune size.

Second, rain-producing clouds may cover half of Titan at any given time (Tokano et al., 2006). Precipitation rates may not necessarily increase toward higher latitudes, currently high northern latitudes, but evaporation rates are likely lower at these higher latitudes. This would allow the lakes to persist and also allow dune-forming sediments to remain wetted for longer periods of time, with the result that the saltation threshold is increased for the wetted sediments and transport rates would be reduced (Nickling, 1994). The saltation threshold 
has been estimated to be around $1 \mathrm{~m} / \mathrm{s}$ for dry sediments (Lorenz, 2010). Recent global circulation models indicate that this threshold is only reached about every 14 Earth years, near the Titan equinox (the most recent of which occurred in 2009), when near-surface winds are reversed briefly from westward to eastward (Lorenz et al., 2010; Tokano, 2010). During the rest of the Titan year, eastward winds blow at around $0.5 \mathrm{~m} / \mathrm{s}$ and westward winds remain near $0.2 \mathrm{~m} / \mathrm{s}$. It is unknown how much the saltation threshold would be increased by wetting the sediments with liquid methane, but wet sediment transport should only be possible during the equinox. The rest of the year would be dominated by depositional hiatus.

Titan's dunes may have reconstitution times of up to 14 times longer than dunes of the same size on Earth even though transportation rates on both worlds are roughly comparable (Lorenz et al., 2006). If on Earth, dunes of Titan's size would be similar in age to those found in the Namib Sand Seas, around 42k years, then on Titan, with winds that reach the saltation threshold only every 14 Earth years, Titan's dunes may be estimated to have a reconstitution time of around $600 \mathrm{k}$ years. This is a minimum time that is based on the assumption that when winds reach sufficient speeds for saltation, surface sediments are available to be transported (i.e., not stabilized by moisture). It is also possible that sediments are only transported during a portion of the time near the equinox and not the entire duration, which would increase the reconstitution time. With such long reconstitution times, changes in wind regime would need to be large in 
scale and stable for thousands of years before there would be an observable difference in dune morphology, far longer than Cassini's operational lifetime.

7.3 Effect of the Atmospheric Boundary Layer on Dune Parameters Lorenz et al., (2010) discuss two fundamental scaling parameters that can control the size of dunes. First, the saturation length ( $\left.\mathrm{L}_{\mathrm{sat}}\right)$. This is the length over which all the grains that can be mobilized by wind of a particular velocity are set in motion. Elementary dunes form and coalesce into larger and larger dune forms until they reach equilibrium with current wind/sediment conditions or reach the second scaling parameter, the thickness of the atmospheric boundary layer. (Breed and Grow, 1979; Hersen et al., 2002; Claudin and Andreotti, 2006). The static stability at the top of the atmospheric boundary layer provides a "cap" that limits dune growth like the water surface does for subaqueous dunes; the dunes will only grow so far into the cap layer (that is the atmospheric boundary layer for subaerial dunes or the water surface for subaqueous dunes) because the shear stress increases near the cap layer preventing sediment accumulation near the top of the dune (Claudin and Andreotti, 2006; Lorenz et al., 2010). Dune spacing is generally 12 times dune height (Lorenz et al., 2010). Limiting dune height also limits dune spacing.

Direct measurements of Titan's boundary layer are not available so an approximation is used as defined by Andreotti et al., (2009). Application of this approximation to Titan yields an atmospheric boundary layer of between 2 and 4 $\mathrm{km}$. The calculated values are in agreement with measurements made on 
RADAR swaths T21, 25, 41, and 41 HiSAR by Lorenz et al. (2010). While there are a number of dunes measured for the current study whose spacing measured higher than $4 \mathrm{~km}, 82.5 \%$ measure between the calculated $2-4 \mathrm{~km}$ boundary layer thickness with the most abundant spacings between 2 and $3 \mathrm{~km}$. The mean spacing for all dunes measured is $2.7 \mathrm{~km}$ is within the calculated height range of the boundary layer.

The trend of decreasing dune width and spacing with increasing northern latitude is evidence that Titan's dunes are evolving over time. Given enough time forming under a certain set of conditions, for example a $3 \mathrm{~km}$ boundary layer, the dunes will evolve becoming more and more mature (i.e. increasing uniformity of morphology, increasing dune size and spacing) until they reach a steady state or the conditions are changed. The steady state to which Titan's dunes are currently evolving is dictated partly by the atmospheric boundary layer. The trend of dune spacings is evidence that the southern dunes have spent more time in the current conditions and have come closer to the steady state condition of $\sim 3 \mathrm{~km}$ spacing as dictated by Titan's 3km atmospheric boundary layer.

\subsection{Implications of a Single Population}

The cumulative probability plots of width and spacing of Titan's dunes indicate there is a single population across the satellite. This has several implications for Titan's climate and how dunes have responded to it in the recent geologic past. The first possibility is that dune-forming conditions have been 
uniform across the entire moon over the recent geologic history of Titan. The second possibility is that there has only ever been a single period of dune building on Titan punctuated by periods of hiatus or non-deposition such as the time between the spring and autumn equinox. The third possibility is that there have been multiple periods of dune building that produced different populations of dunes, but current conditions have been present long enough to erase any evidence of previous periods at the scale of features visible to Cassini RADAR.

On Earth, plotting data from dune fields that are separated by long distances would reveal several populations since those fields are not being acted upon by the same mechanisms. Indeed, it is true that even data from the same dune fields can reveal several different populations (as in the Namib and Agneitir). Plotting data from widely separated areas on Titan, however, does not reveal multiple populations. Cumulative probability plots of data from all five study swaths show a single population despite the fact that the location of each study swath and dune field may vary by many degrees of longitude and latitude. This is evidence that dune-forming conditions on Titan are uniform across the moon. A recent study of dune orientations on Titan supports this. Lorenz and Radebaugh (2009) examined the crest orientations of dunes all across Titan and were able to show that the vast majority of them, with the exception of those interacting with local topography, were aligned parallel to the equator.

Using the same principles of a single set of conditions producing a single population, there is on Titan only a single set of conditions suitable for dune 
building at resolutions visible to Cassini RADAR. This is not to say, however, that there were no other conditions in the past that led to different dune parameters, only that evidence for prior conditions has not been preserved. It also does not say that the conditions for which we have current evidence have been in operation continuously since dune building began.

Bristow et al., (2007) were able to show that dune growth in the northern Namib Desert has been episodic. Ground Penetrating RADAR (GPR) data were combined with OSL dates obtained from cores along an E-W transect of a N-S trending linear dune. The oldest sediments in this particular dune were deposited during a building episode that ended 5,700 years ago. This first phase was followed by a depositional hiatus that lasted until about 2,410 years ago when the second phase of building began. This phase lasted until about 140 years ago and was followed by a short hiatus. The final phase represents a reworking of the surface sediments during the past 50 years.

There is no way obtain specific numbers and durations of deposition and hiatuses for Titan's dunes, though models of climate cycles may provide some feel for the frequency of these periods. As mentioned previously, wind velocities are likely most favorable for saltation and sediment transport during Titan's equinox, which occurs every 14 Earth years, and is likely the time during which winds are most active. Dunes in the Namib Sand Sea are subject to similar variations in sediment transport throughout the year (Lancaster, 1989). Most sediment transport occurs during the summer months when the wind circulation 
in Central and Southern Namibia is strongly influenced by the South Atlantic anticyclone and winds sufficient to move sediments are achieved about $50 \%$ of the time. During the winter months winds that rise above the saltation threshold decline to only $25 \%$ - 30\% of the time (Lancaster, 1989).

The last possibility is that there have been other periods of dune building that were different than those currently observed, but enough time has passed since the current conditions began that any evidence of previous dune-building has been erased. Evidence for previous episodes is best found in GPR profiles or trenching, and obtaining OSL dates for sediments, none of which are currently available.

\subsection{Conclusions}

The study of morphologies and parameters of dunes on Titan, including primarily width and spacing, has yielded several important conclusions. First, the dunes measured in the five study swaths, T21, 23, 28, 44 and 48, are all linear in form. Titan's dunes have an average width of $1.33 \mathrm{~km}$, wider than analogous dunes in the Namib Sand Sea with average width of $0.88 \mathrm{~km}$. Titan's dunes are also widely spaced with an average crest spacing of $2.62 \mathrm{~km}$, in contrast with those in the Namib Sand Sea, which have an average spacing of $2.16 \mathrm{~km}$. Based on their size alone, Titan's dunes should be classified as complex and should host superimposed and flanking dunes, but no such features are visible on Titan's dunes given the data sets available. This suggests Titan's dunes are of a new 
category not seen currently on Earth, very large simple linear dunes. Despite the difference in average width and spacing between terrestrial dunes and those on Titan, the relationship between dune width and spacing, namely that dune width tends to be about half dune spacing, observed on Earth's dunes also holds for Titan dunes. This is further evidence that terrestrial dunes can be used as analogues for Titan's dunes and vice versa. Also even though Titan is 800 million miles away from Earth and the materials for making dunes are vastly different, the essential physical dune-forming processes are similar.

Second, Titan's dunes show characteristics indicative of being very mature and long-lived features including large widths and spacings, the general absence of flanking features and uniform morphology. Since dunes are the result of interactions between the atmosphere and sediments, all of these attributes are evidence of long-term stability of the wind regime and/or growth of the dunes toward a steady state partially dictated by the thickness of the atmospheric boundary layer on Titan. Dunes on Earth of such sizes have long reconstruction times, such as the largest dunes in the Namib Sand Sea with reconstruction times of $42 \mathrm{k}$ years. Dune reconstitution times on Titan must include frequent periods of depositional hiatus, because the saltation threshold may only be reached near the Titan equinox every 14 Earth years (Tokano et al. 2010). Therefore, reconstitution times could be as long as 600k years or more. Thus, changes in wind regime would need to be large in scale and stable for thousands of years before noticeable differences in large dune forms could be observed, far longer 
than Cassini's operational lifetime. The atmospheric boundary layer on Titan, a "capping" function that limits dune growth and crest spacing, has been calculated to be between 2 and $4 \mathrm{~km}$, directly relatable to crest spacing. The majority of dunes on Titan (82.5\%) have crest spacings that fall between 2 and $4 \mathrm{~km}$, which is further evidence for their maturity and stability in the current wind regime.

Third, two important trends are found in the dune-field parameters of dune width and crest spacing. Both width and spacing of dunes on Titan decrease with northward increasing latitude, in all measured regions except in small isolated dune fields such as those found in swath T23 and 28. This trend is consistent with, but not limited to, increased dune sediment stabilization, a function of increasing relative amounts of moisture to the north (Aharonson et al., 2009; Le Gall et al., 2011), the existence of shorter construction times with latitude increasing to the north, and growth of the dunes toward a steady state size. The trend of decreasing spacing with increasing northern latitude may be the result of southern dunes being older and having more closely approached the spacing limitation of $2-4 \mathrm{~km}$ as dictated by Titan's atmospheric boundary layer.

Finally, though higher-resolution images and larger sample size may eventually reveal another story, it is apparent based on cumulative sizeprobability plots that all dunes measured at different locations across Titan comprise a single population. This suggests that, unlike analogous dunes in the Namib and Agneitir Sand Seas, dune-forming conditions currently on Titan are 
either the only dune-friendly conditions in the moon's history, or the current conditions have been stable and active long enough to erase any evidence of past conditions.

Pattern analysis of Titan's dune-field parameters is a useful tool for reconstructing the surface evolution history of this unique moon. Since this study only accounts for a limited number of Titan's dunes, collecting similar data sets and applying pattern analysis to dunes from all of the RADAR images that contain dunes will tell a more complete story of how the surface and duneforming conditions on Titan have changed through time.

\section{References}

Aharonson, O., Hayes, A. G., Lunine, J. I., Lorenz, R. D., Allison, M. D., Elachi, C., 2009. An asymmetric distribution of lakes on Titan as a possible consequence of orbital forcing. Nature Geosci. 2, 851-854.

Andreotti, B., Fourriere, A., Ould-Kaddour, F., Murray, B., Claudin, P., 2009. Giant aeolian dune size determined by the average depth of the atmospheric boundary layer. Nature. 457, 1120-1123.

Bagnold, R. A., 1941. The physics of blown sand and desert dunes. Methuen, London.

Barnes, J. W., Brown, R. H., Soderblom, L., Sotin, C., Le Mouèlic, S., Rodriguez, S., Jaumann, R., Beyer, R. A., Buratti, B. J., Pitman, K., Baines, K. H., Clark, R., Nicholson, P., 2008. Spectroscopy, morphometry, and photoclinometry of Titan's dunefields from Cassini/VIMS. Icarus. 195, 400-414.

Bishop, S. R., Momiji, H., Carretero-González, R., Warren, A., 2002. Modelling Desert Dune Fields Based on Discrete Dynamics. Discrete Dynamics in Nature and Society. 7, 7-17.

Bourke, M. C., Lancaster, N., Fenton, L. K., Parteli, E. J. R., Zimbelman, J. R., Radebaugh, J., 2010. Extraterrestrial dunes: An introduction to the special issue on planetary dune systems. Geomorphology. 121, 1-14.

Breed, C. S., Grow, T., Morphology and distribution of dunes in sand seas observed by remote sensing. In: E. D. McKee, (Ed.), A Study of Global Sand Seas, 1979, pp. 253-302. 
Bristow, C. S., Bailey, S. D., Lancaster, N., 2000. The sedimentary structure of linear sand dunes. Nature. 406, 56-59.

Bristow, C. S., Duller, G. A. T., Lancaster, N., 2007. Age and dynamics of linear dunes in the Namib Desert. Geology. 35, 555-558.

Brown, R., Baines, K., Bellucci, G., Bibring, J. P., Buratti, B., Capaccioni, F., Cerroni, P., Clark, R., Coradini, A., Cruikshank, D., Drossart, P., Formisano, V., Jaumann, R., Langevin, Y., Matson, D., McCord, T., Mennella, V., Miller, E., Nelson, R., Nicholson, P., 2005. TheCassiniVisual And Infrared Mapping Spectrometer (Vims) Investigation. Space Science Reviews. 115, 111-168.

Bullard, J. E., Thomas, D. S. G., Livingstone, I., Wiggs, G. F. S., 1995. Analysis of linear sand dune morphological variability, southwestern Kalahari desert. Geomorphology. 11, 189-203.

Claudin, P., Andreotti, B., 2006. A scaling law for aeolian dunes on Mars, Venus, Earth, and for subaqueous ripples. Earth and Planetary Science Letters. $252,30-44$.

Coustenis, A., Lellouch, E., Sicardy, B., Roe, H., Earth-based perspective and preCassini-Huygens knowledge of Titan. In: R. H. Brown, et al., Eds.), Titan from Cassini-Huygens. Springer, Springer, 2009, pp. 9-34.

Edgett, K. S., Malin, M. C., 2000. New views of Mars eolian activity, materials, and surface properties: Three vignettes from the Mars Global Surveyor Mars Orbiter Camera. J. Geophys. Res. 105, 1623-1650.

Elachi, C., Allison, M. D., Borgarelli, L., Encrenaz, P., Im, E., Janssen, M. A., Johnson, W. T. K., Kirk, R. L., Lorenz, R. D., Lunine, J. I., Muhleman, D. O., Ostro, S. J., Picardi, G., Posa, F., Rapley, C. G., Roth, L. E., Seu, R., Soderblom, L. A., Vetrella, S., Wall, S. D., Wood, C. A., Zebker, H. A., 2004. Radar: The Cassini Titan Radar Mapper. Space Science Reviews. 115, 71-110.

Elachi, C., Wall, S., Allison, M., Anderson, Y., Boehmer, R., Callahan, P., Encrenaz, P., Flamini, E., Franceschetti, G., Gim, Y., Hamilton, G., Hensley, S., Janssen, M., Johnson, W., Kelleher, K., Kirk, R., Lopes, R., Lorenz, R., Lunine, J., Muhleman, D., Ostro, S., Paganelli, F., Picardi, G., Posa, F., Roth, L., Seu, R., Shaffer, S., Soderblom, L., Stiles, B., Stofan, E., Vetrella, S., West, R., Wood, C., Wye, L., Zebker, H., 2005. Cassini Radar Views the Surface of Titan. Science. 308, 970-974.

Elachi, C., Wall, S., Janssen, M., Stofan, E., Lopes, R., Kirk, R., Lorenz, R., Lunine, J., Paganelli, F., Soderblom, L., Wood, C., Wye, L., Zebker, H., Anderson, Y., Ostro, S., Allison, M., Boehmer, R., Callahan, P., Encrenaz, P., Flamini, E., Francescetti, G., Gim, Y., Hamilton, G., Hensley, S., Johnson, W., Kelleher, K., Muhleman, D., Picardi, G., Posa, F., Roth, L., Seu, R., Shaffer, S., Stiles, B., Vetrella, S., West, R., 2006. Titan Radar Mapper observations from Cassini's T3 fly-by. Nature. 441, 709-713. 
Elachi, C. I., E., Roth, L. E., Werner, C. L., 1991. Cassini Titan Radar Mapper. Proceedings of the IEEE 79, 867-880.

Ewing, R. C., Kocurek, G., Lake, L. W., 2006. Pattern analysis of dune-field parameters. Earth Surface Processes and Landforms. 31, 1176-1191.

Ewing, R. C., Peyret, A.-P. B., Kocurek, G., Bourke, M., 2010. Dune field pattern formation and recent transporting winds in the Olympia Undae Dune Field, north polar region of Mars. J. Geophys. Res. 115, E08005.

Greeley, R., Arvidson, R. E., Elachi, C., Geringer, M. A., Plaut, J. J., Saunders, R. S., Schubert, G., Stofan, E. R., Thouvenot, E. J. P., Wall, S. D., Weitz, C. M., 1992. Aeolian Features on Venus: Preliminary Magellan Results. J. Geophys. Res. 97, 13319-13345.

Greeley, R., Iversen, J. D., 1985. Wind as a Geological Process on Earth Mars, Venus and Titan. Cambridge University Press, Cambridge.

Hayes, A., Aharonson, O., Callahan, P., Elachi, C., Gim, Y., Kirk, R., Lewis, K., Lopes, R., Lorenz, R., Lunine, J., Mitchell, K., Mitri, G., Stofan, E., Wall, S., 2008. Hydrocarbon lakes on Titan: Distribution and interaction with a porous regolith. Geophys. Res. Lett. 35, L09204.

Hersen, P., Douady, S., eacute, phane, Andreotti, B., 2002. Relevant Length Scale of Barchan Dunes. Physical Review Letters. 89, 264301.

Janssen, M. A., Lorenz, R. D., West, R., Paganelli, F., Lopes, R. M., Kirk, R. L., Elachi, C., Wall, S. D., Johnson, W. T. K., Anderson, Y., Boehmer, R. A., Callahan, P., Gim, Y., Hamilton, G. A., Kelleher, K. D., Roth, L., Stiles, B., Le Gall, A., 2009. Titan's surface at 2.2-cm wavelength imaged by the Cassini RADAR radiometer: Calibration and first results. Icarus. 200, 222239.

Kerr, R. C., Nigra, J. O., 1952. Eolian Sand Control. Bulletin of the American Association of Petroleum Geologists. 36, 1541-1573.

Kocurek, G., The aeolian rock record. In: A. Goudie, I. Livingstone, Eds.), Aeolian Environments, Sediments and Landforms. John Wiley, London, 1999, pp. $239-259$.

Kocurek, G., Ewing, R. C., 2005. Aeolian dune field self-organization implications for the formation of simple versus complex dune-field patterns. Geomorphology. 72, 94-105.

Kocurek, G., Ewing, R. C., Mohrig, D., 2010. How do bedform patterns arise? New views on the role of bedform interactions within a set of boundary conditions. Earth Surface Processes and Landforms. 35, 51-63.

Kocurek, G., Robinson, N. I., Sharp, J. M., 2001. The response of the water table in coastal aeolian systems to changes in sea level. Sedimentary Geology. 139, $1-13$.

Kuiper, G. P., 1944. Titan: A satellite with an atmosphere. Astrophysical Journal. $100,5$.

Lancaster, N., 1988. Controls of eolian dune size and spacing. Geology. 16, 972975. 
Lancaster, N., 1989. The Namib Sand Sea: dune fonns, processes and sediments. A.A. Balkema, Rotterdam.

Lancaster, N., 1995. Geomorphology of Desert Dunes. Routledge, London. Lancaster, N., 2006. Linear Dunes on Titan. Science. 312, 702-703.

Lancaster, N., Kocurek, G., Singhvi, A., Pandey, V., Deynoux, M., Ghienne, J.-F., Lo, K., 2002. Late Pleistocene and Holocene dune activity and wind regimes in the western Sahara Desert of Mauritania. Geology. 30, 991-994.

Le Gall, A., Janssen, M. A., Wye, L. C., Hayes, A. G., Radebaugh, J., Savage, C., Zebker, H., Lorenz, R. D., Lunine, J. I., Kirk, R. L., Lopes, R. M. C., Wall, S., Callahan, P., Stofan, E. R., Farr, T., 2011. Cassini SAR, radiometry, scatterometry and altimetry observations of Titan's dune fields. Icarus. $213,608-624$.

Lebreton, J.-P., Witasse, O., Sollazzo, C., Blancquaert, T., Couzin, P., Schipper, A.M., Jones, J. B., Matson, D. L., Gurvits, L. I., Atkinson, D. H., Kazeminejad, B., Perez-Ayucar, M., 2005. An overview of the descent and landing of the Huygens probe on Titan. Nature. 438, 758-764.

Lebreton, J. P., Matson, D. L., 2002. The Huygens Probe: Science, Payload and Mission Overview. Space Science Reviews. 104, 59-100.

Livingstone, I., 1989. Monitoring surface change on a Namib linear dune. Earth Surface Processes and Landforms. 14, 317-332.

Livingstone, I., 1993. A decade of surface change on a Namib linear dune. Earth Surface Processes and Landforms. 18, 661-664.

Lopes, R. M. C., Mitchell, K. L., Stofan, E. R., Lunine, J. I., Lorenz, R., Paganelli, F., Kirk, R. L., Wood, C. A., Wall, S. D., Robshaw, L. E., Fortes, A. D., Neish, C. D., Radebaugh, J., Reffet, E., Ostro, S. J., Elachi, C., Allison, M. D., Anderson, Y., Boehmer, R., Boubin, G., Callahan, P., Encrenaz, P., Flamini, E., Francescetti, G., Gim, Y., Hamilton, G., Hensley, S., Janssen, M. A., Johnson, W. T. K., Kelleher, K., Muhleman, D. O., Ori, G., Orosei, R., Picardi, G., Posa, F., Roth, L. E., Seu, R., Shaffer, S., Soderblom, L. A., Stiles, B., Vetrella, S., West, R. D., Wye, L., Zebker, H. A., 2007.

Cryovolcanic features on Titan's surface as revealed by the Cassini Titan Radar Mapper. Icarus. 186, 395-412.

Lorenz, R. D., 2006. The Exploration of Titan. Johns Hopkins APL Technical Digest. 27, 11.

Lorenz, R. D., 2010. Winds of Change on Titan. Science. 329, 519-520.

Lorenz, R. D., Claudin, P., Andreotti, B., Radebaugh, J., Tokano, T., 2010. A 3 km atmospheric boundary layer on Titan indicated by dune spacing and Huygens data. Icarus. 205, 719-721.

Lorenz, R. D., Lopes, R. M., Paganelli, F., Lunine, J. I., Kirk, R. L., Mitchell, K. L., Soderblom, L. A., Stofan, E. R., Ori, G., Myers, M., Miyamoto, H., Radebaugh, J., Stiles, B., Wall, S. D., Wood, C. A., 2008. Fluvial channels on Titan: Initial Cassini RADAR observations. Planetary and Space Science. 56, 1132-1144. 
Lorenz, R. D., Radebaugh, J., 2009. Global pattern of Titan's dunes: Radar survey from the Cassini prime mission. Geophys. Res. Lett. 36, L03202.

Lorenz, R. D., Wall, S., Radebaugh, J., Boubin, G., Reffet, E., Janssen, M., Stofan, E., Lopes, R., Kirk, R., Elachi, C., Lunine, J., Mitchell, K., Paganelli, F., Soderblom, L., Wood, C., Wye, L., Zebker, H., Anderson, Y., Ostro, S., Allison, M., Boehmer, R., Callahan, P., Encrenaz, P., Ori, G. G., Francescetti, G., Gim, Y., Hamilton, G., Hensley, S., Johnson, W., Kelleher, K., Muhleman, D., Picardi, G., Posa, F., Roth, L., Seu, R., Shaffer, S., Stiles, B., Vetrella, S., Flamini, E., West, R., 2006. The Sand Seas of Titan: Cassini RADAR Observations of Longitudinal Dunes. Science. 312, 724-727.

Lorenz, R. D., Wood, C. A., Lunine, J. I., Wall, S. D., Lopes, R. M., Mitchell, K. L., Paganelli, F., Anderson, Y. Z., Wye, L., Tsai, C., Zebker, H., Stofan, E. R., 2007. Titan's young surface: Initial impact crater survey by Cassini RADAR and model comparison. Geophys. Res. Lett. 34, L07204.

Matson, D., Spilker, L., Lebreton, J.-P., 2002. The Cassini/Huygens Mission to the Saturnian System. Space Science Reviews. 104, 1-58.

McKee, E. D., Sedimentary structures in dunes. In: E. D. McKee, (Ed.), A Study of Global Sand Seas. U. S. Government Printing Office, Washington, D.C., 1979, pp. 83-134.

Munyikwa, K., 2005. The role of dune morphologenetic history in the interpretation of linear dune luminescence chronologies: a review of linear dune dynamics. Progress in Physical Geography. 29, 317-336.

Nickling, W. G., Eolian sediment transport and deposition. In: K. Pye, (Ed.), Sediment Transport and Depositional Processes. Blackwell Scientific Publication, Oxford, 1994, pp. 293-350.

Paganelli, F., Janssen, M. A., Lopes, R. M., Stofan, E., Wall, S. D., Lorenz, R. D., Lunine, J. I., Kirk, R. L., Roth, L., Elachi, C., 2008. Titan's surface from the Cassini RADAR radiometry data during SAR mode. Planetary and Space Science. 56, 100-108.

Paganelli, F., Janssen, M. A., Stiles, B., West, R., Lorenz, R. D., Lunine, J. I., Wall, S. D., Callahan, P., Lopes, R. M., Stofan, E., Kirk, R. L., Johnson, W. T. K., Roth, L., Elachi, C., the Radar, T., 2007. Titan's surface from Cassini RADAR SAR and high resolution radiometry data of the first five flybys. Icarus. 191, 211-222.

Porco, C. C., Baker, E., Barbara, J., Beurle, K., Brahic, A., Burns, J. A., Charnoz, S., Cooper, N., Dawson, D. D., Del Genio, A. D., Denk, T., Dones, L., Dyudina, U., Evans, M. W., Fussner, S., Giese, B., Grazier, K., Helfenstein, P., Ingersoll, A. P., Jacobson, R. A., Johnson, T. V., McEwen, A., Murray, C. D., Neukum, G., Owen, W. M., Perry, J., Roatsch, T., Spitale, J., Squyres, S., Thomas, P., Tiscareno, M., Turtle, E. P., Vasavada, A. R., Veverka, J., Wagner, R., West, R., 2005. Imaging of Titan from the Cassini spacecraft. Nature. 434, 159-168. 
Radebaugh, J., Lorenz, R., Farr, T., Paillou, P., Savage, C., Spencer, C., 2010.

Linear dunes on Titan and earth: Initial remote sensing comparisons. Geomorphology. 121, 122-132.

Radebaugh, J., Lorenz, R. D., Kirk, R. L., Lunine, J. I., Stofan, E. R., Lopes, R. M. C., Wall, S. D., 2007. Mountains on Titan observed by Cassini Radar. Icarus. 192, 77-91.

Radebaugh, J., Lorenz, R. D., Lunine, J. I., Wall, S. D., Boubin, G., Reffet, E., Kirk, R. L., Lopes, R. M., Stofan, E. R., Soderblom, L., Allison, M., Janssen, M., Paillou, P., Callahan, P., Spencer, C., the Cassini Radar, T., 2008. Dunes on Titan observed by Cassini Radar. Icarus. 194, 690-703.

Reffet, E., Courrech du Pont, S., Hersen, P., Douady, S., 2010. Formation and stability of transverse and longitudinal sand dunes. Geology. 38, 491-494.

Ritter, D. F., Kochel, R. C., Miller, J. R., 2002. Process Geomorphology. Waveland Press, Long grove.

Smith, B. A., Soderblom, L., Beebe, R., Boyce, J., Briggs, G., Bunker, A., Collins, S. A., Hansen, C. J., Johnson, T. V., Mitchell, J. L., Terrile, R. J., Carr, M., Cook, A. F., Cuzzi, J., Pollack, J. B., Danielson, G. E., Ingersoll, A., Merton, E. D., Hunt, G. E., Masursky, H., Shoemaker, E., Morrison, D., Owen, T., Sagan, C., Veverka, J., Strom, R., Suomi, V. E., 1981. Encounter with Saturn: Voyager 1 Imaging Science Results. Science. 212, 163-191.

Smith, G. R., Strobel, D. F., Broadfoot, A. L., Sandel, B. R., Shemansky, D. E., Holberg, J. B., 1982. Titan's Upper Atmosphere: Composition and Temperature from the EUV Solar Occultation Results. J. Geophys. Res. 87, 1351-1359.

Soderblom, L. A., Kirk, R. L., Lunine, J. I., Anderson, J. A., Baines, K. H., Barnes, J. W., Barrett, J. M., Brown, R. H., Buratti, B. J., Clark, R. N., Cruikshank, D. P., Elachi, C., Janssen, M. A., Jaumann, R., Karkoschka, E., Mouélic, S. L., Lopes, R. M., Lorenz, R. D., McCord, T. B., Nicholson, P. D., Radebaugh, J., Rizk, B., Sotin, C., Stofan, E. R., Sucharski, T. L., Tomasko, M. G., Wall, S. D., 2007. Correlations between Cassini VIMS spectra and RADAR SAR images: Implications for Titan's surface composition and the character of the Huygens Probe Landing Site. Planetary and Space Science. 55, 2025-2036.

Stofan, E. R., Elachi, C., Lunine, J. I., Lorenz, R. D., Stiles, B., Mitchell, K. L., Ostro, S., Soderblom, L., Wood, C., Zebker, H., Wall, S., Janssen, M., Kirk, R., Lopes, R., Paganelli, F., Radebaugh, J., Wye, L., Anderson, Y., Allison, M., Boehmer, R., The lakes of Titan. Vol. 445. Nature Publishing Group, 2007, pp. 61-64.

Stokes, S., Thomas, D. S. G., Shaw, P. A., 1997. New chronological evidence for the nature and timing of linear dune development in the southwest Kalahari Desert. Geomorphology. 20, 81-93.

Tokano, T., 2010. Relevance of fast westerlies at equinox for the eastward elongation of Titan's dunes. Aeolian Research. 2, 113-127. 
Tokano, T., McKay, C. P., Neubauer, F. M., Atreya, S. K., Ferri, F., Fulchignoni, M., Niemann, H. B., 2006. Methane drizzle on Titan. Nature. 442, 432-435.

Triola, M. F., 2004. Elementary Statistics. Pearson Education, Boston.

Tsoar, H., 1983. Dynamic processes acting on a longitudinal (seif) sand dune. Sedimentology. 30, 567-578.

Tsoar, H., 1984. The formation of seif dunes from barchans - a discussion. Zeitschrift für Geomorphologie. 28, 999-1003.

Tsoar, H., 1989. Linear dunes - forms and formation. Progress in Physical Geography. 13, 507-528.

Wang, X., Dong, Z., Zhang, J., Qu, J., 2004. Formation of the complex linear dunes in the central Taklimakan Sand Sea, China. Earth Surface Processes and Landforms. 29, 677-686.

Warren, A., Allison, D., 1998. The paleoenvironmental significance of dune size hierarchies. Palaeogeography, Palaeoclimatology, Palaeoecology. 137, 289303.

Warren, A., Knot, P., Desert dunes: a short review of needs in desert dune research and a recent study of micro-meteorological dune initiation mechanisms. In: M.E.Brookfield, T.S.Ahlbrandt, Eds.), Eolian Sediments and Processes. Elsevier, Amsterdam, 1983.

Werner, B. T., 1995. Eolian dunes: Computer simulations and attractor interpretation. Geology. 23, 1107-1110.

Werner, B. T., Kocurek, G., 1997. Bed-form dynamics: Does the tail wag the dog? Geology. 25, 771-774.

Werner, B. T., Kocurek, G., 1999. Bedform spacing from defect dynamics. Geology. 27, 727-730.

Wilson, I. G., 1973. Ergs. Sedimentary Geology. 10, 77-106.

Wood, C. A., Lorenz, R., Kirk, R., Lopes, R., Mitchell, K., Stofan, E., 2010. Impact craters on Titan. Icarus. 206, 334-344. 
Figure Captions

Figure 1

Dune type diagram relating sand availability to wind direction variability (modified from Bishop et al., (2002)) Linear dunes, the main focus of this study, show a range of sand availability and wind direction variability.

Figure 2

Photos taken by the author of (a) a simple linear dune near Qattanaya, Egypt located around 29 $53^{\prime} 34$ N, 30¹5'47 E; and (b) a complex dune located in the Great Sand Sea just south of Siwa, Egypt. Note the relatively straight, single crest line and absence of flanking dune features in (a) and the prominent crest line of the main dune running across the photo with a set of flanking dunes running obliquely to the main crest line in (b).

Figure 3

Landsat 7 image of linear dunes in the Namib Sand Sea clearly showing both flanking, superimposed dunes and dentate peaks. Image is centered at around $24^{\circ} 08^{\prime} 55^{\prime \prime} \mathrm{S}$ and $15^{\circ} 04^{\prime} 30^{\prime \prime} \mathrm{E}$ (image courtesy of NASA).

Figure 4

The global location of 36 of Cassini's RADAR swaths, shown as grayscale strips overlain on a VIMS/ISS basemap. The five swaths sampled for this study are labeled. The approximate location of each measurement is marked in red; these red points roughly outline the dune fields observed in these swaths.

Figure 5

Cumulative probability chart from (a) crest lengths in the White Sands and (b) crest lengths in the Namib Sand Sea (from Ewing et al., 2006). A single line of data points with no breaks or inflection points represents a single lognormal population. Inflection points or breaks in the data separate multiple populations.

Figure 6

Cumulative probability plots of dune spacing from (a) the Namib Sand Sea and (b) the Agneitir Sand Sea (from Ewing et al. 2006). Two inflection points separate three different populations in each location.

Figure 7

Cartoon depicting dune pattern parameters and their measurements. Average dune width and interdune spacing were added to obtain average crest spacing for a given region. 
Figure 8

Section of RADAR swath T23 showing dunes (dark streaks) and interdune areas (lighter areas). Measurements were taken approximately every $5 \mathrm{~km}$ across the dune long axis. Dune widths are measured from one light/dark boundary to the next across the dark dune. Interdune spacing is measured from one light/dark boundary to the next across the light area between dunes. Crest spacing was not directly measured, but approximated by adding the average interdune spacing per degree latitude/longitude to dune width in the same degree latitude/longitude.

Figure 9

Example of Titan's linear dunes from RADAR swath T21 centered at about $10.40^{\circ}$ $\mathrm{N}, 278.94^{\circ} \mathrm{W}$. Like similar terrestrial linear dunes, Titan's dunes are slightly sinuous and generally parallel but do not appear to host superimposed or flanking dunes.

Figure 10

SIR-C image of complex linear dunes in the Namib Sand Sea near Tsondabvlei, Namibia. In this image dunes tend to be highly reflective while interdune areas are less reflective. Note the abundance of flanking dunes particularly in areas where they stand out against the dark interdunes.

Figure 11

The same SIR-C image as in figure 10 but resampled to $\sim 175 \mathrm{~m} /$ pixel similar to Cassini RADAR image resolution. Note that small dunes are detectable against the dark interdune areas. Also note that apparently single crestlines in the unmodified image appear to be multiple dunes in the resampled image.

Figure 12

RADAR image of linear dunes in the Sahara, Egypt. Dunes are dark streaks against a light interdune area. These dunes resemble dunes on Titan. Few, if any, flanking dunes are visible.

Figure 13

Degraded RADAR image of dunes in the Sahara, Egypt. This degraded image resembles those collected by the Cassini spacecraft of Titan's linear dunes.

Figure 14

Histogram of Titans dune widths.

Figure 15

Histogram of Titan's dune spacing. 
Figure 16

Mean dune width and crest spacing per degree latitude for all dune measurements across Titan. Dune width decreases northward while dune spacing shows no correlation with latitude. Error bars are 1-sigma, but in most cases smaller than the symbols used. Some outliers were removed for convenience (see Fig. 23 for complete data set).

Figure 17

Mean dune widths per degree latitude for each study swath. Note that the trend of decreasing width with increasing latitude is visible in most of the study swaths with some exceptions.

Figure 18

Mean dune crest spacing per degree latitude for each of the study swaths. Note that the trend of decreasing dune crest spacing with increasing latitude is present in only a few of the swaths with.

Figure 19

Examples of small, isolated dune fields in (a) swath T28, (b) swath T23 that account for the exceptions in the trend of decreasing dune width and spacing with increasing northern latitude.

Figure 20

Examples of dunes in (a) swath T28, (b) swath T23 that are more regularly spaced and that follow the general trend of decreasing width and increasing spacing closely.

Figure 21

Example of dunes in swath T44. Exceptions to the trend of decreasing width and spacing with increasing latitude in this swath are likely due to measurement error as a result of low contrast between the dune and interdune area and poor resolution at swath boundaries.

Figure 22

Example of dunes from swath T21 where there is very high contrast between the dune and interdune area making measurements of interdune spacing and dune width more accurate and consistent.

Figure 23

Mean dune width and crest spacing per degree latitude for all dune measurements across Titan. Dune width decreases northward while dune spacing shows no correlation with latitude. Error bars are 1-sigma but in most cases smaller than the symbols used. Outliers have not been removed from these data sets. 


\section{Figure 24}

Cumulative probability chart of (a) all widths and (b) all crest spacings measured for this study. The lack of inflection points or breaks in the data suggests that all the dunes measured are of a single population.

Figure 25

Cumulative probability plots of dune width for each of the study swaths. Each plot shows that the dunes measured for each swath belong to single populations.

Figure 26

Cumulative probability plots of dune crest spacing for each of the study swaths. Each plot shows that the dunes measured for each swath belong to single populations with the possible exception of T23.

Figure 27

Scatter diagram showing the correlation between mean dune crest spacing and mean dune width in relation to dune form for various linear dunes around the world and Titan (data from Breed and Grow, 1979 and Lancaster, 1995). Note that most of Titan's dune plot in the upper right quadrant where terrestrial linear dunes plot as complex dunes. 
Figures

Fig. 1

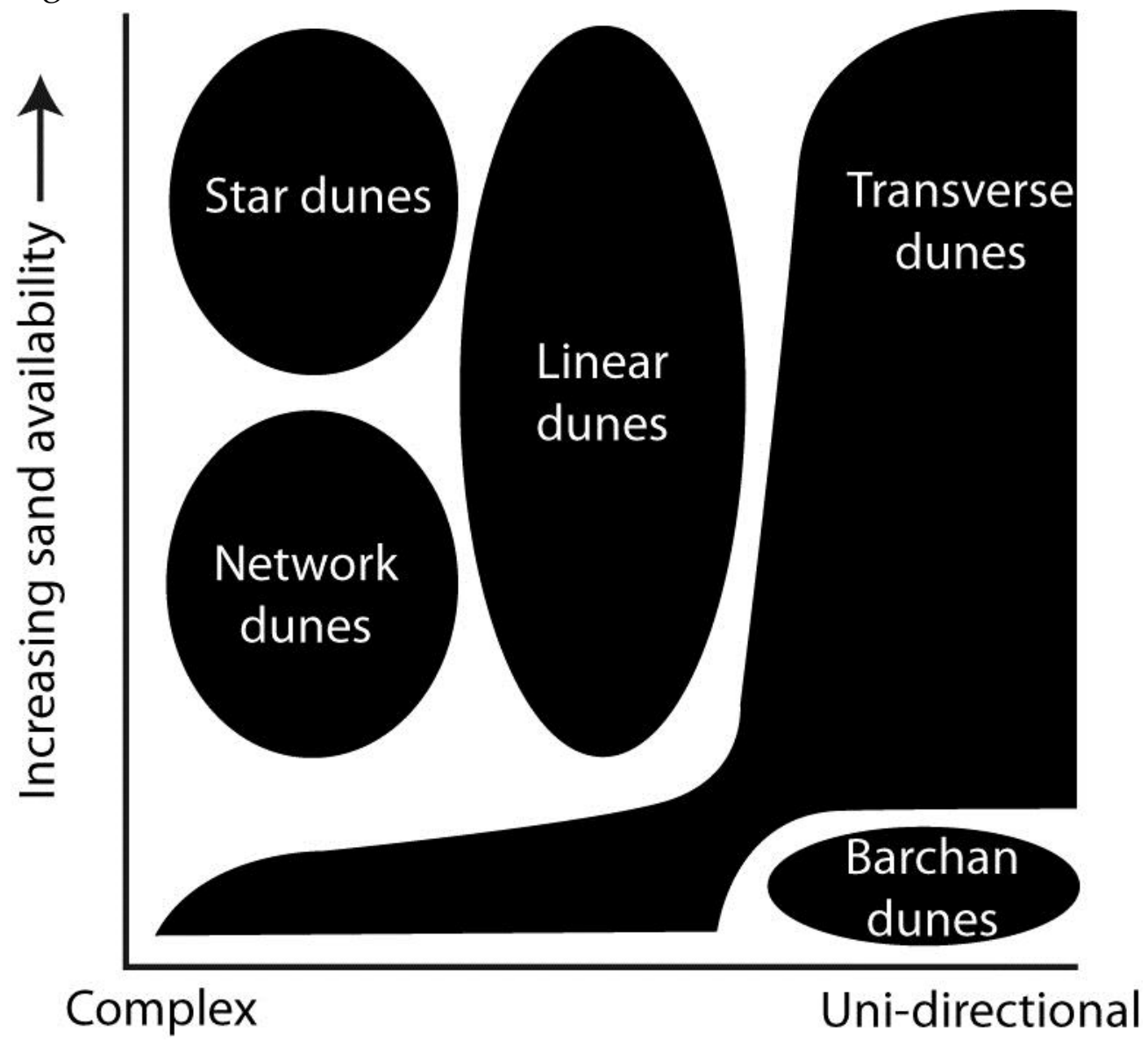

Wind Directional Variability 
Fig. 2
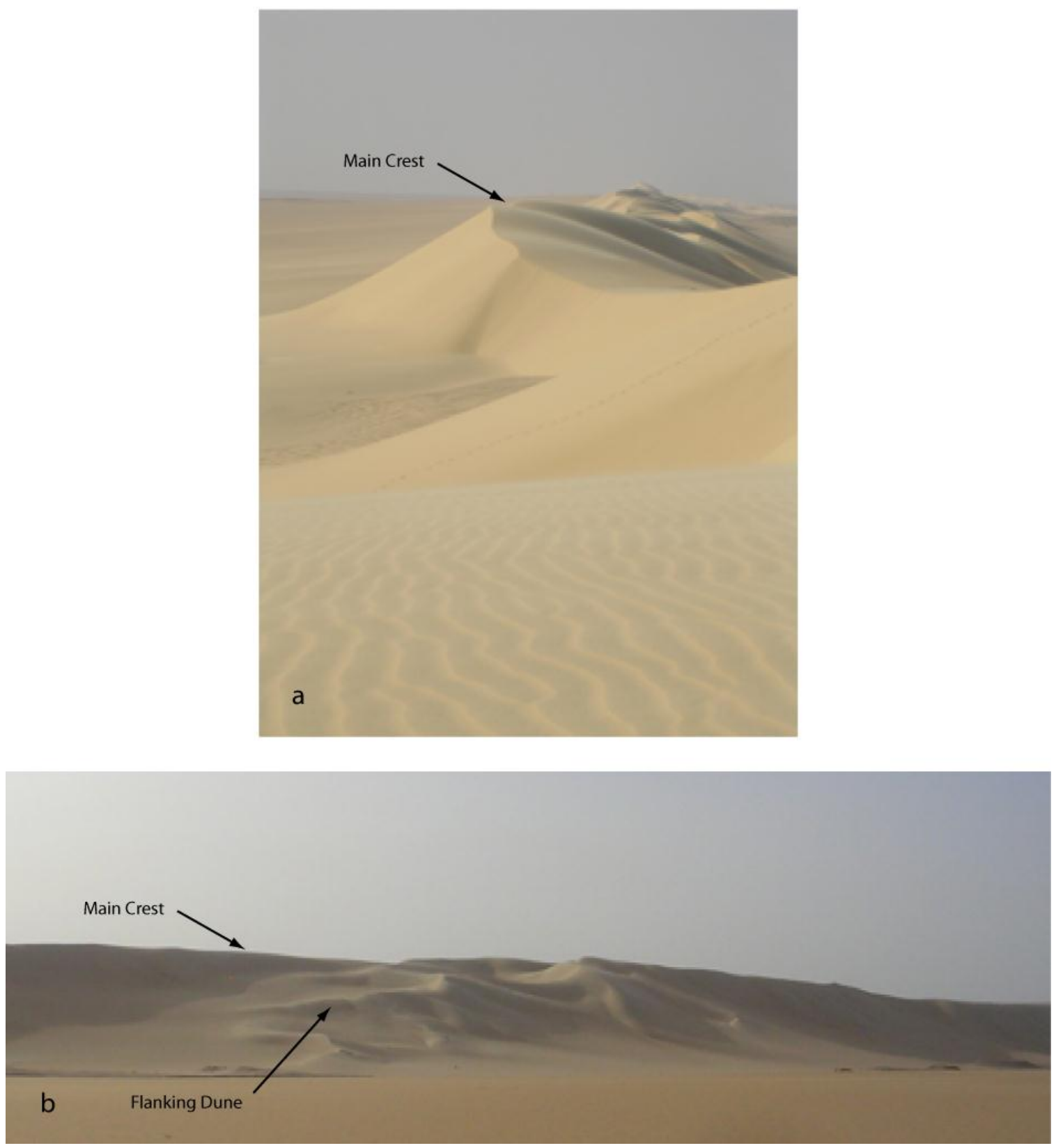
Fig. 3

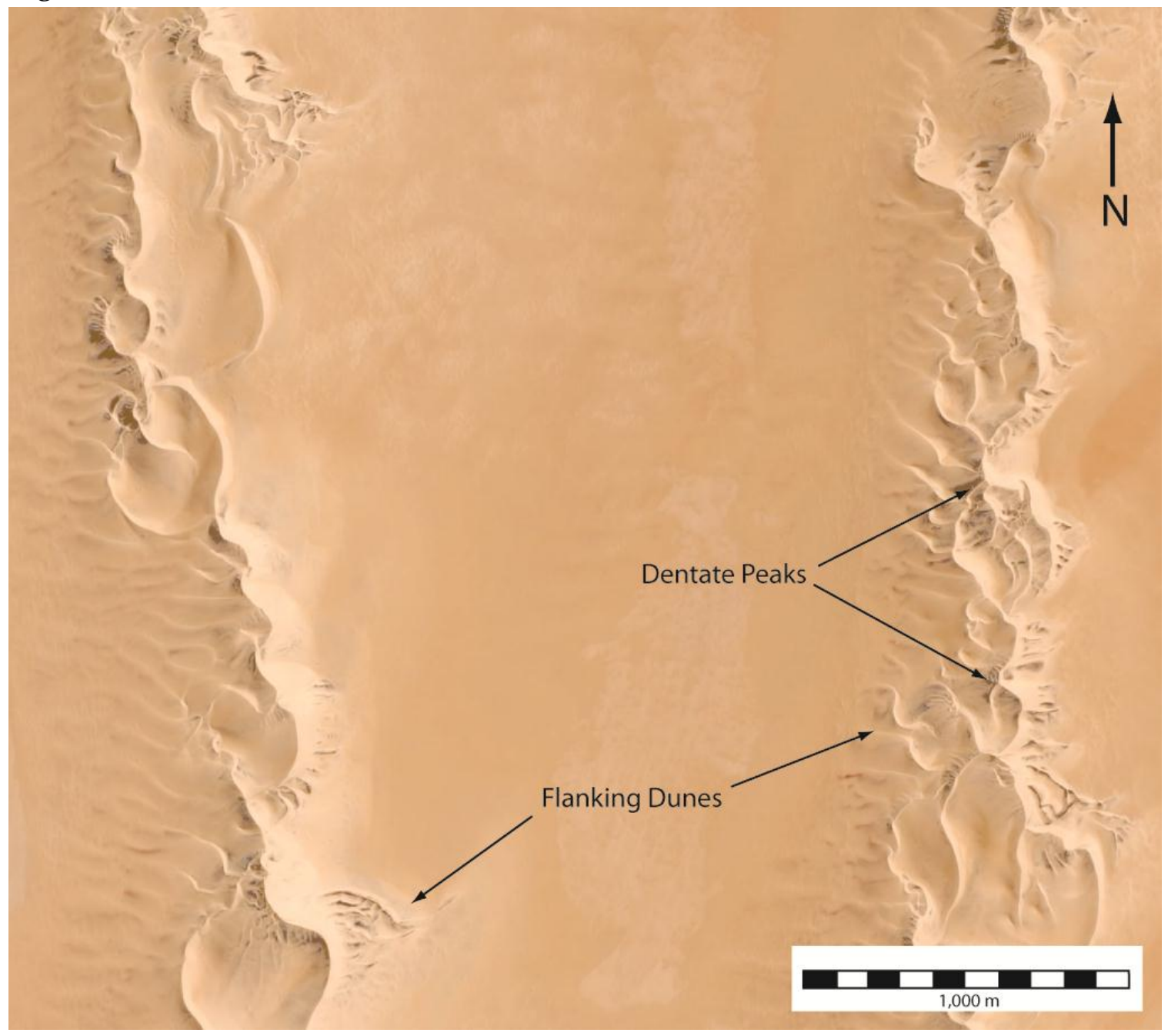


Fig. 4

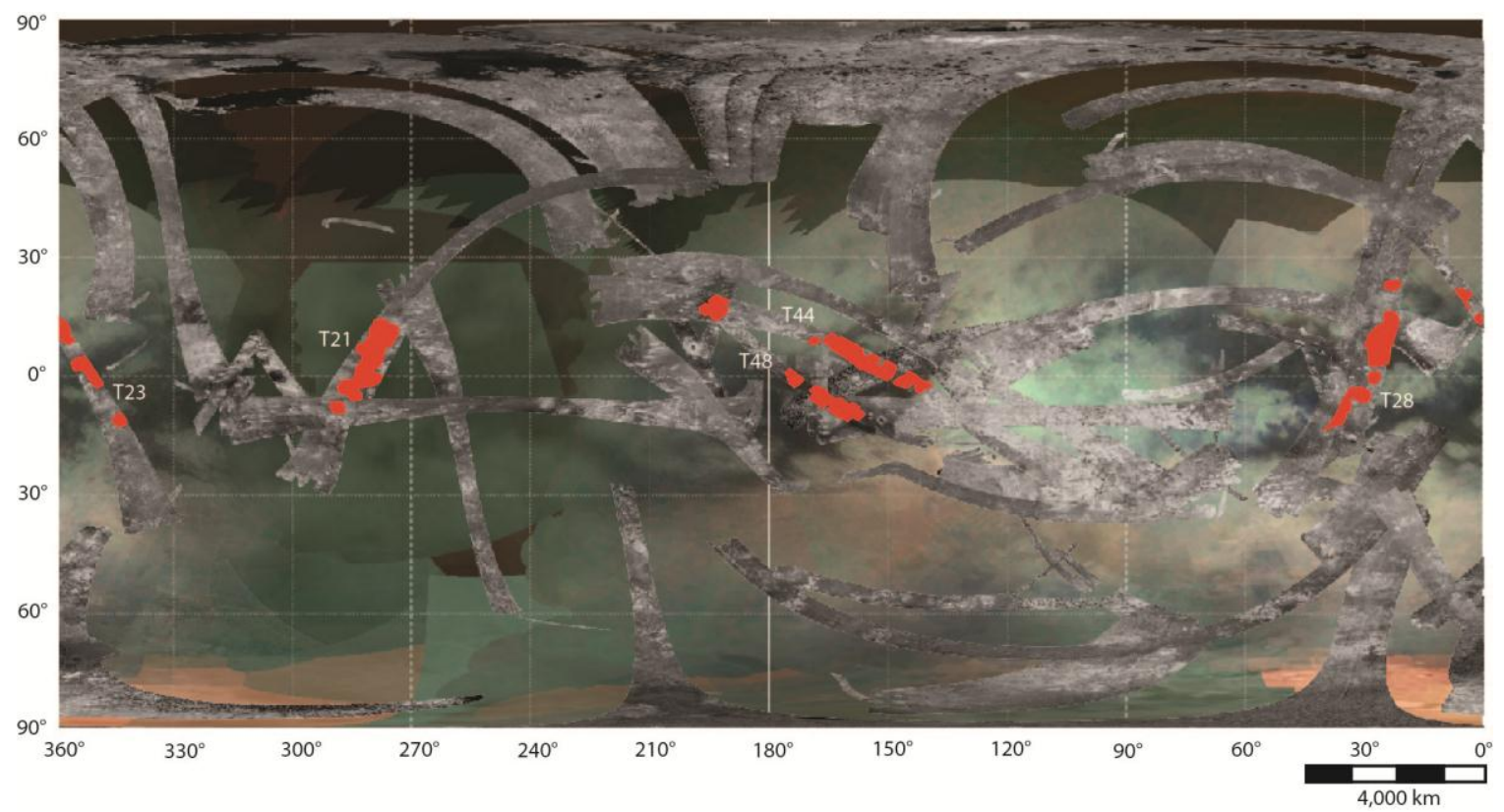


Fig. 5
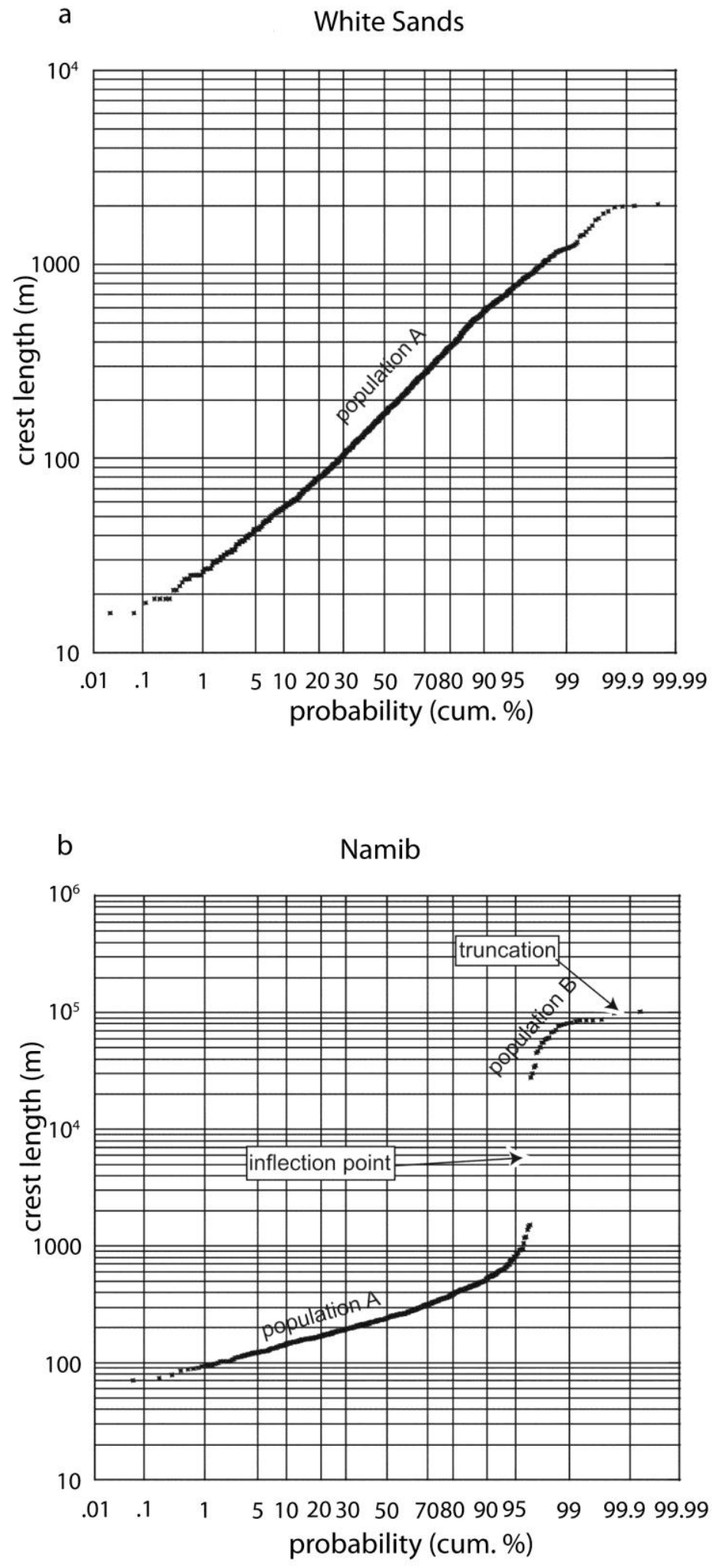
Fig. 6
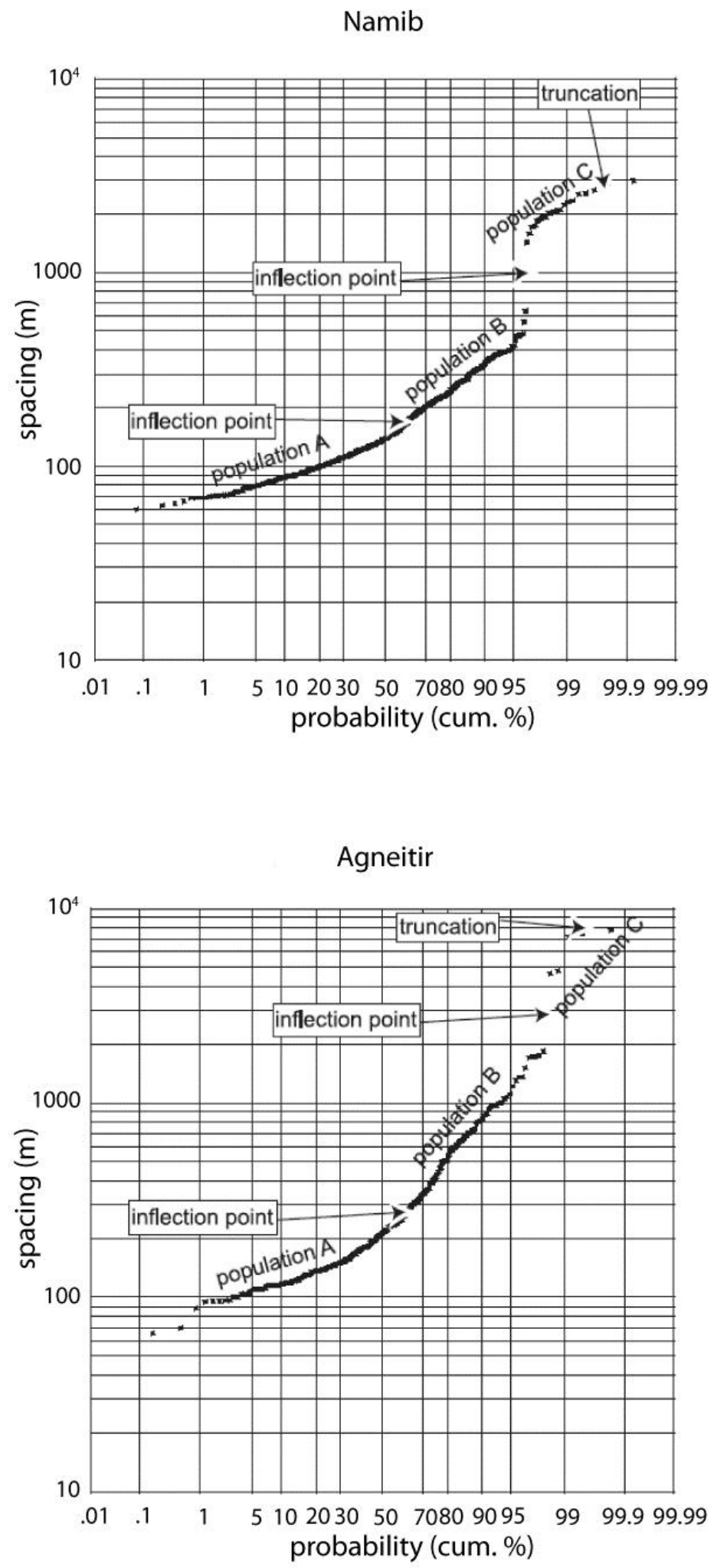
Fig. 7
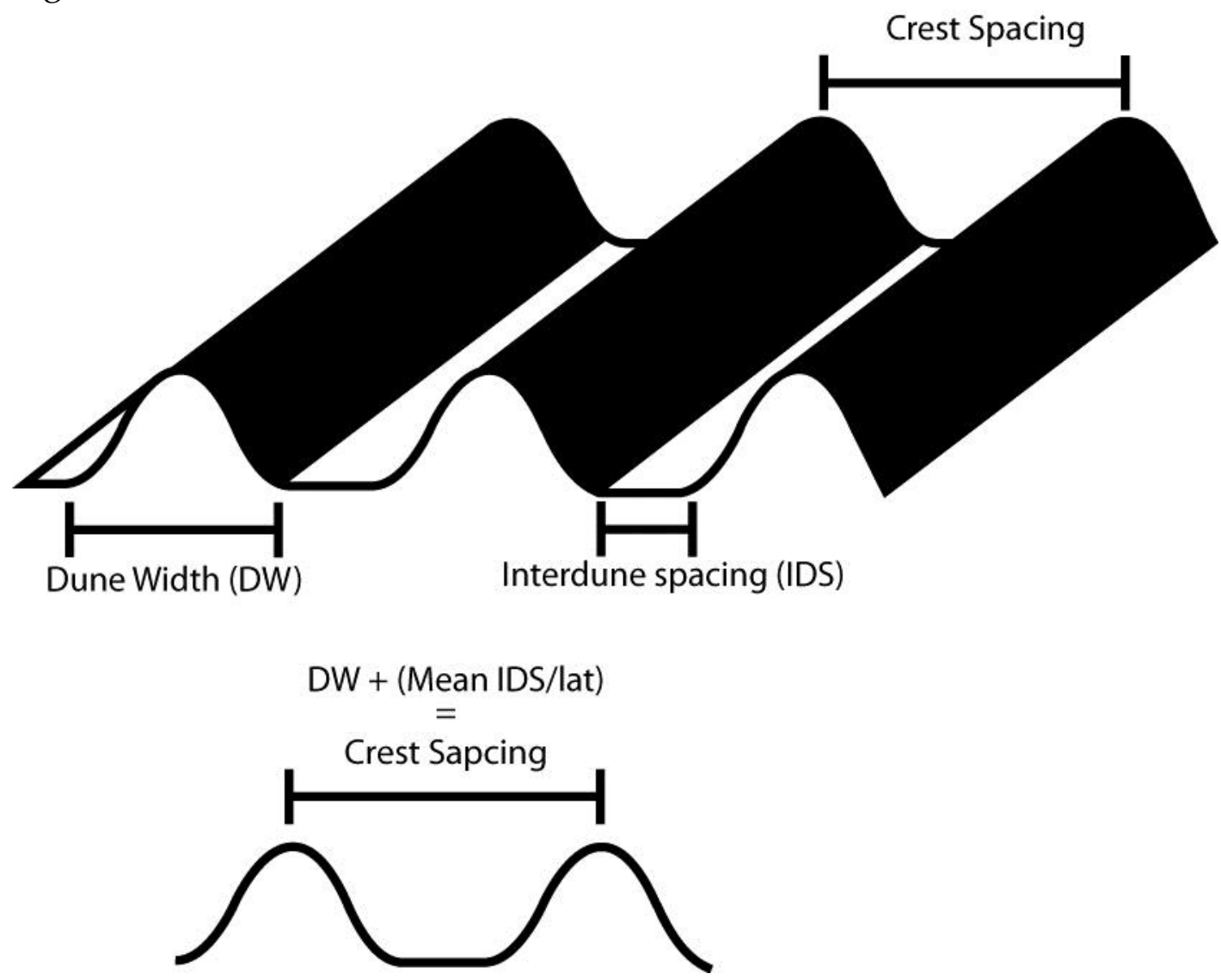
Fig. 8

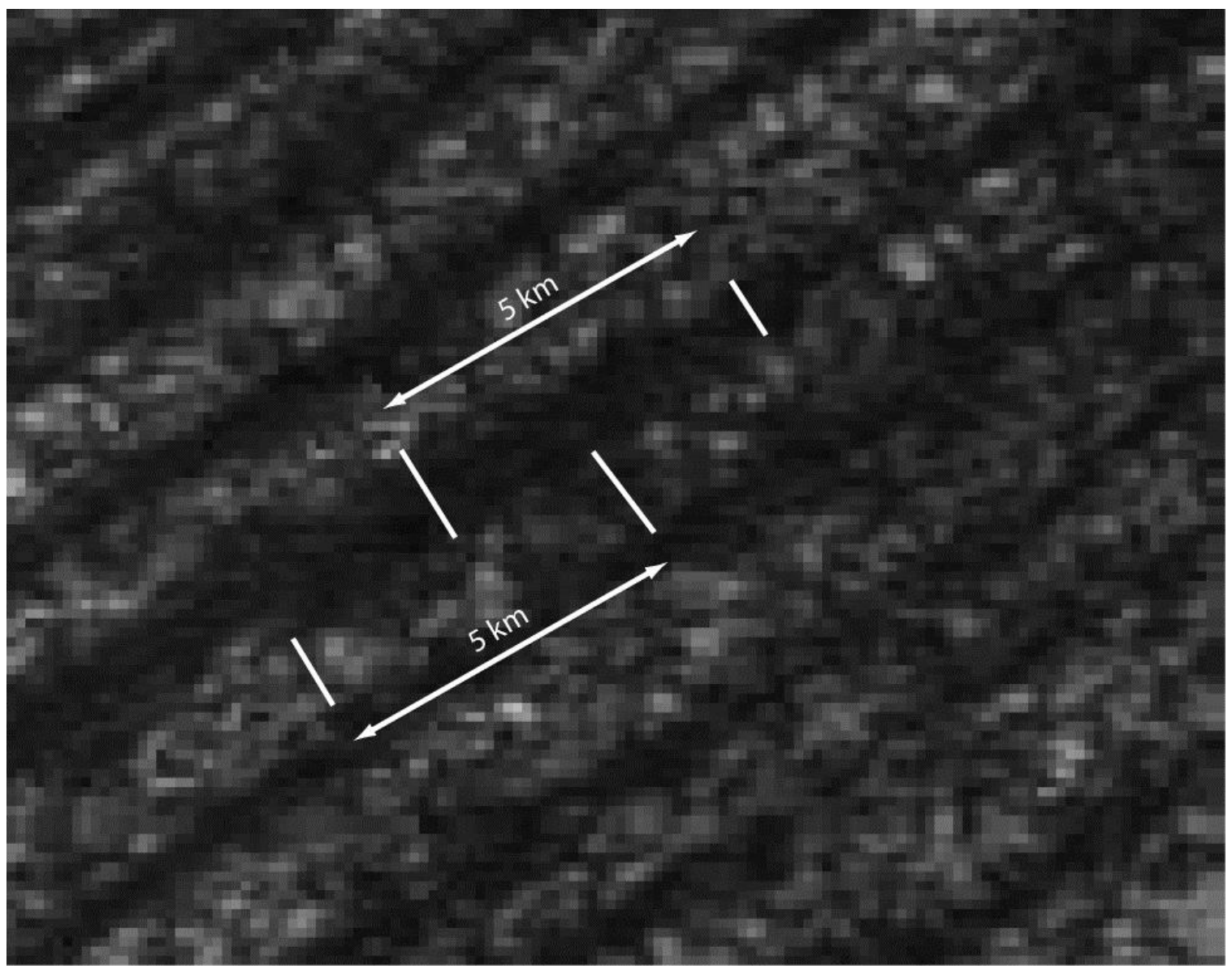


Fig. 9
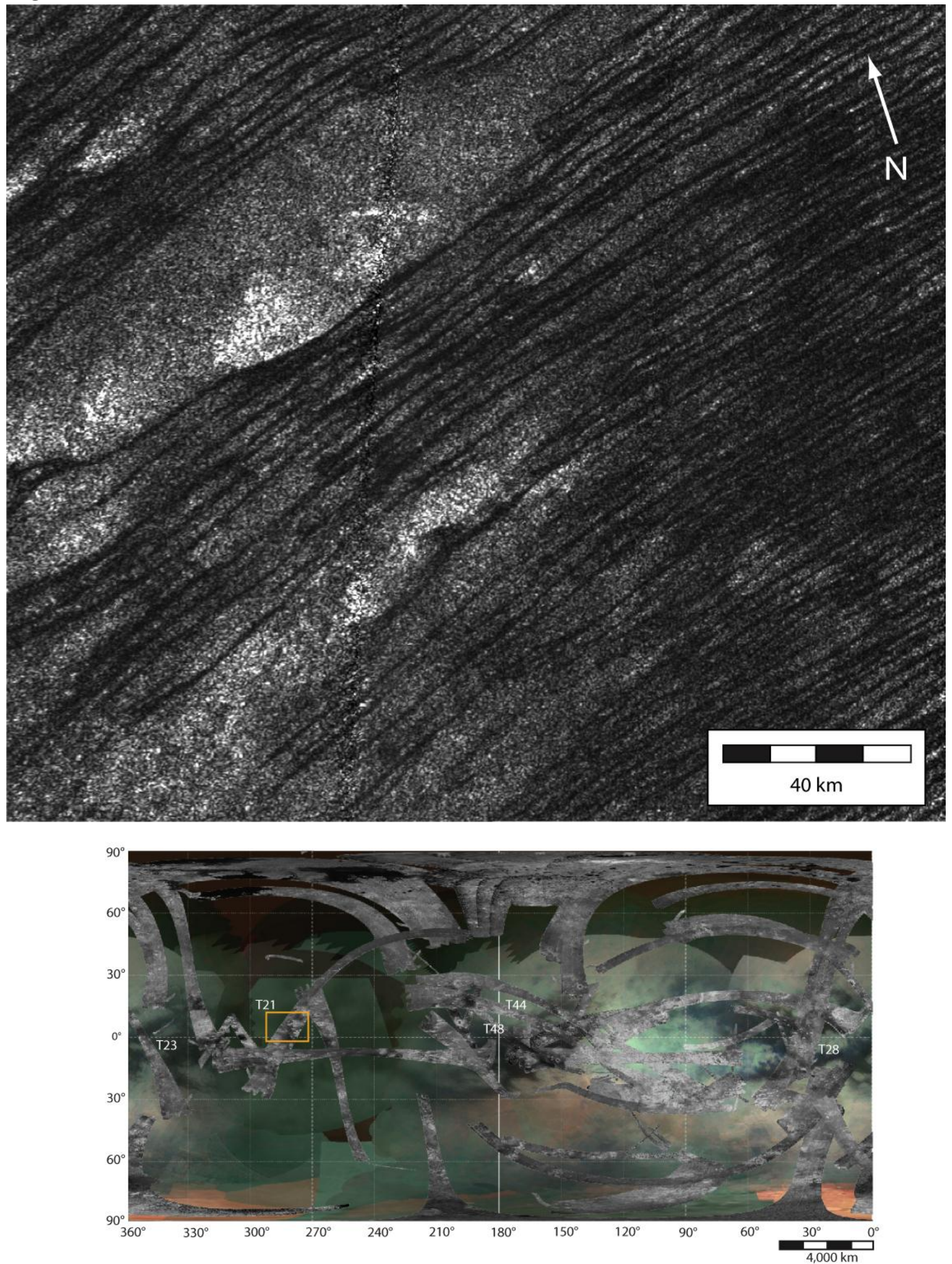
Fig. 10

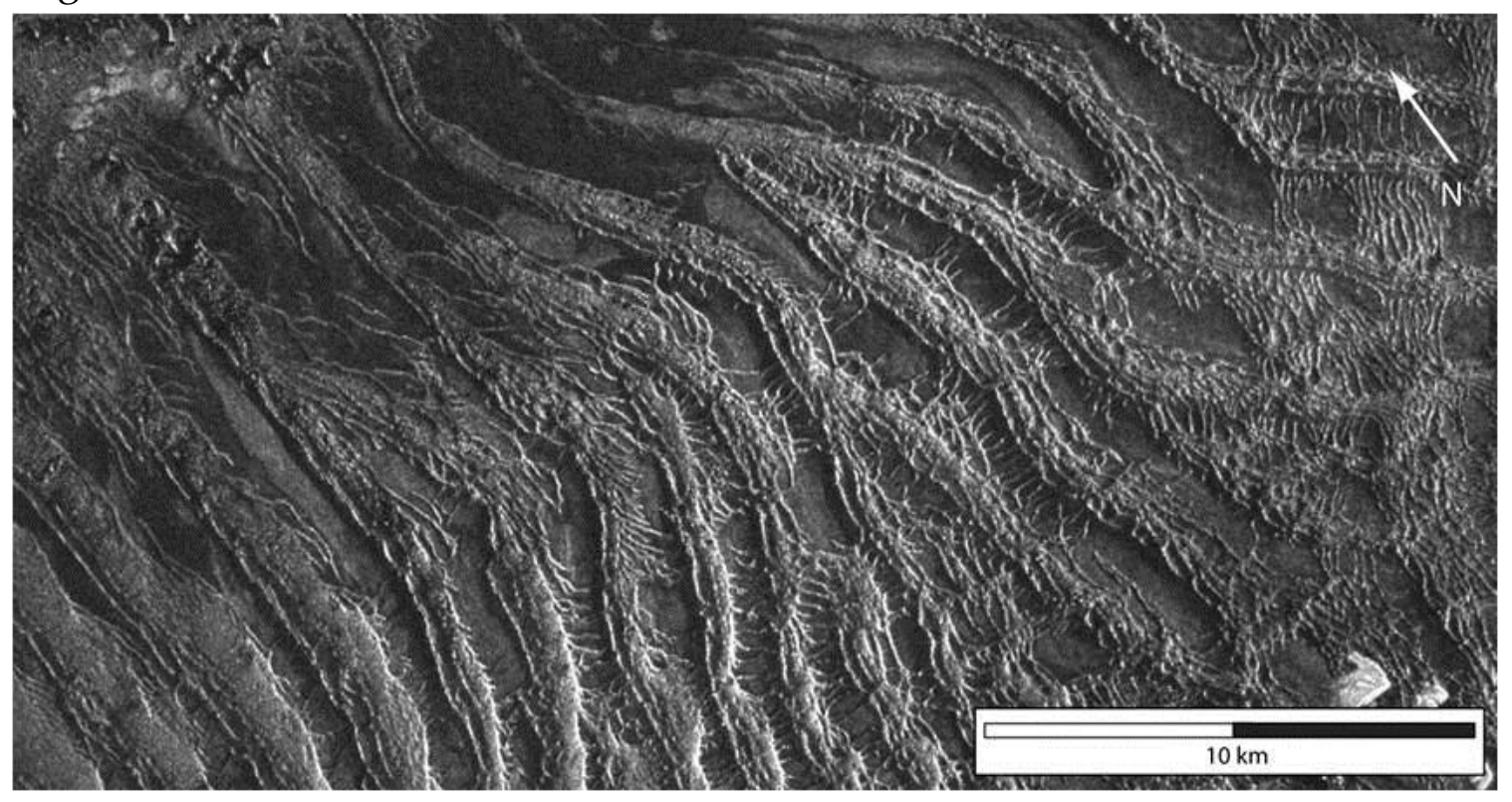


Fig. 11

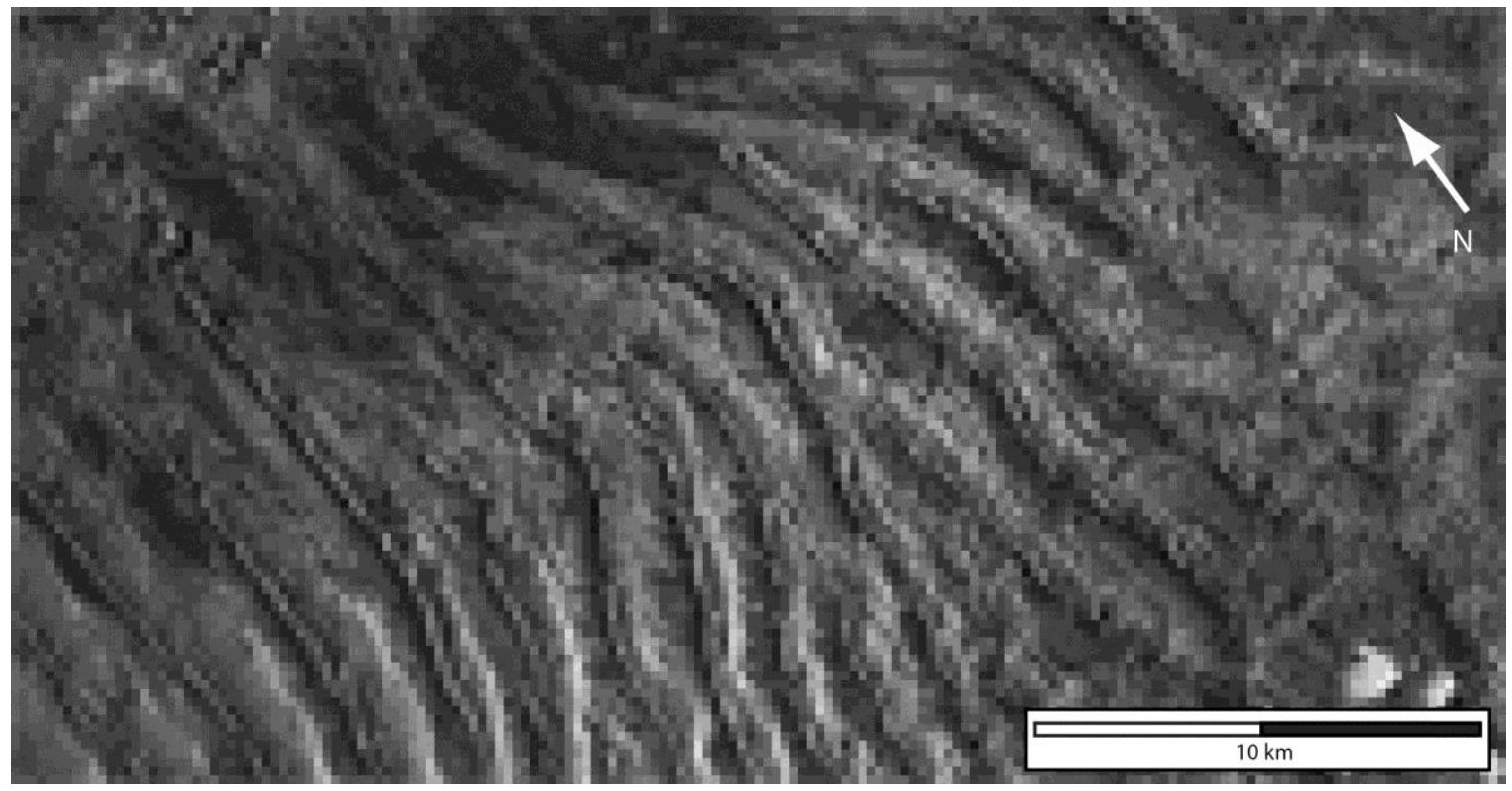


Fig. 12

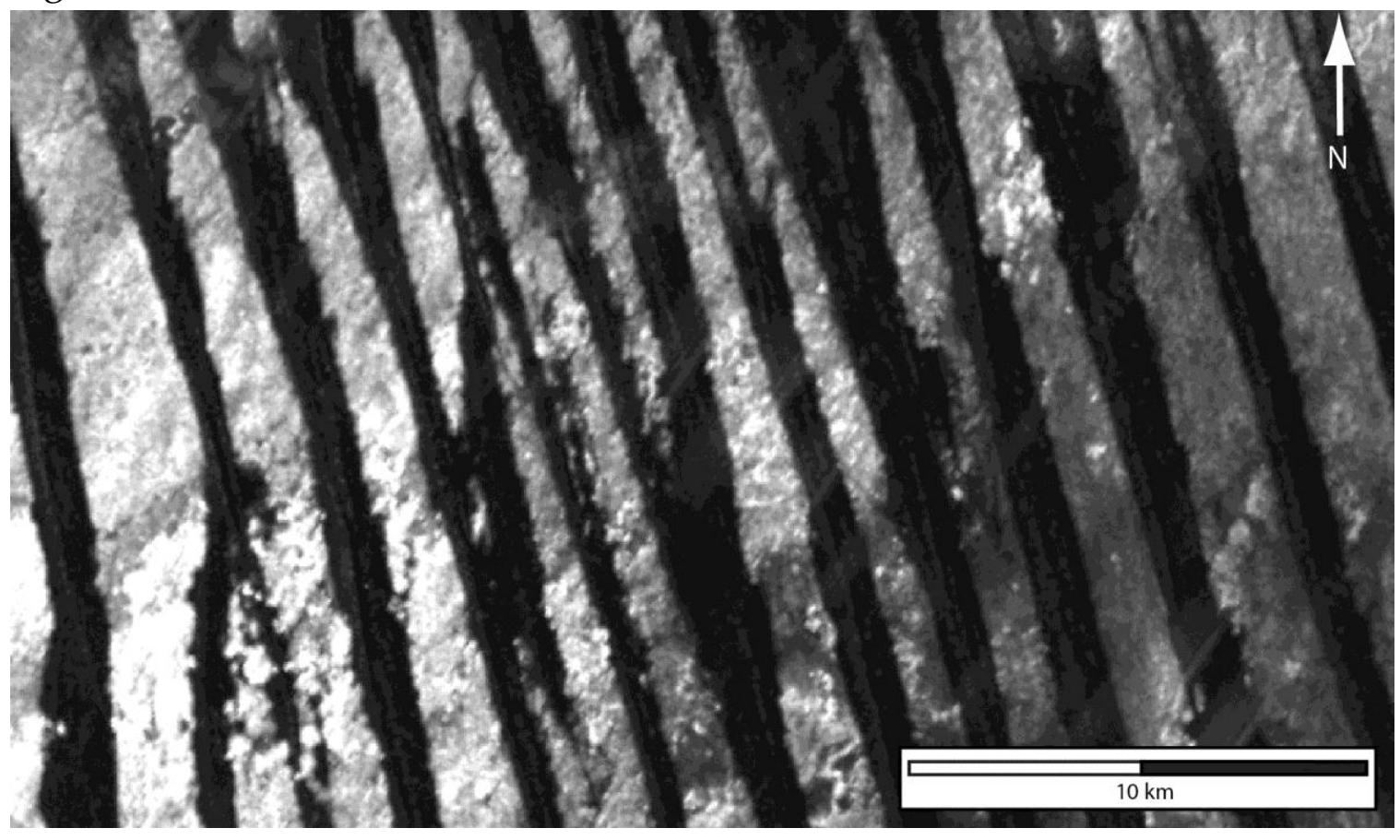


Fig. 13

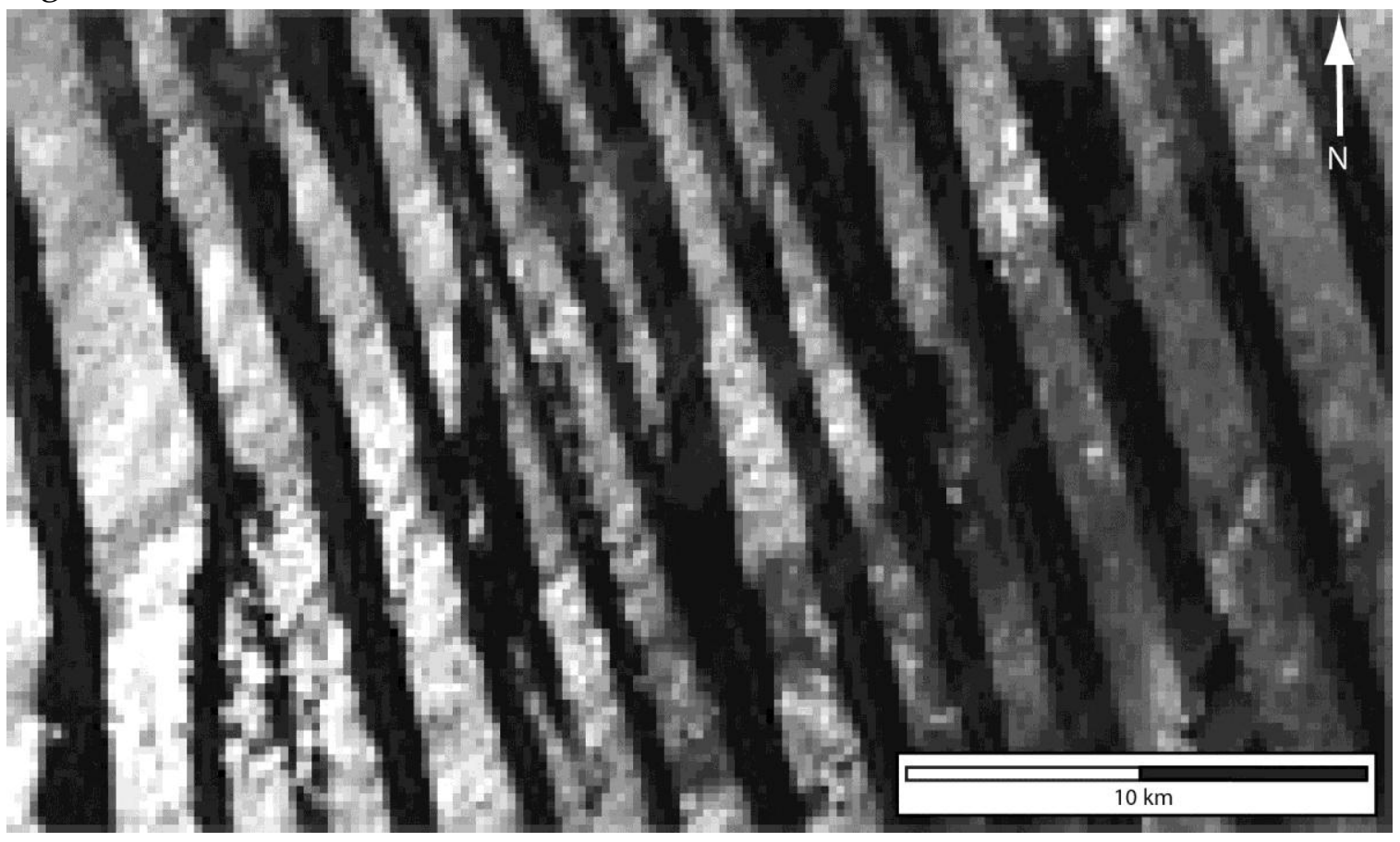


Fig. 14

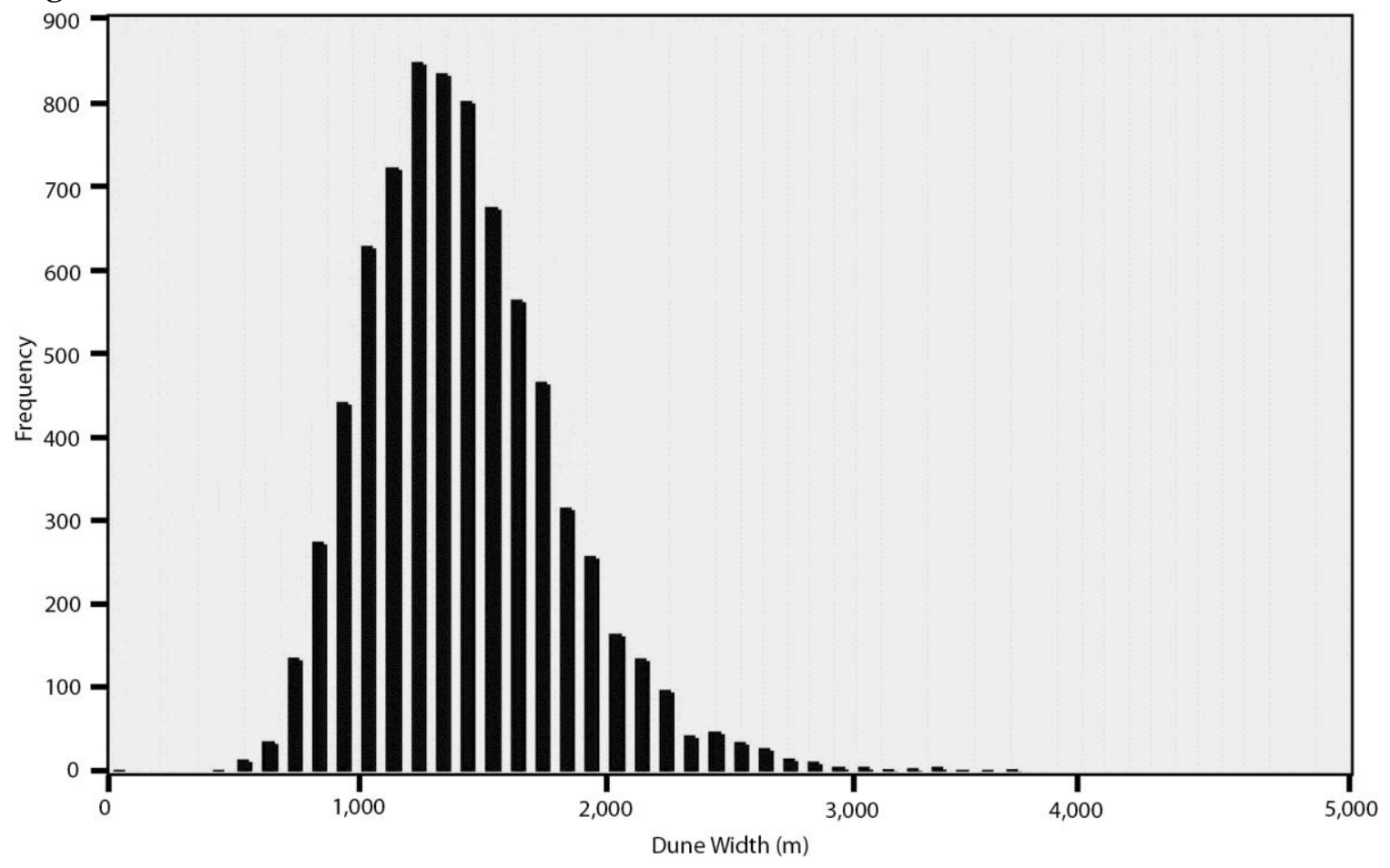


Fig. 15

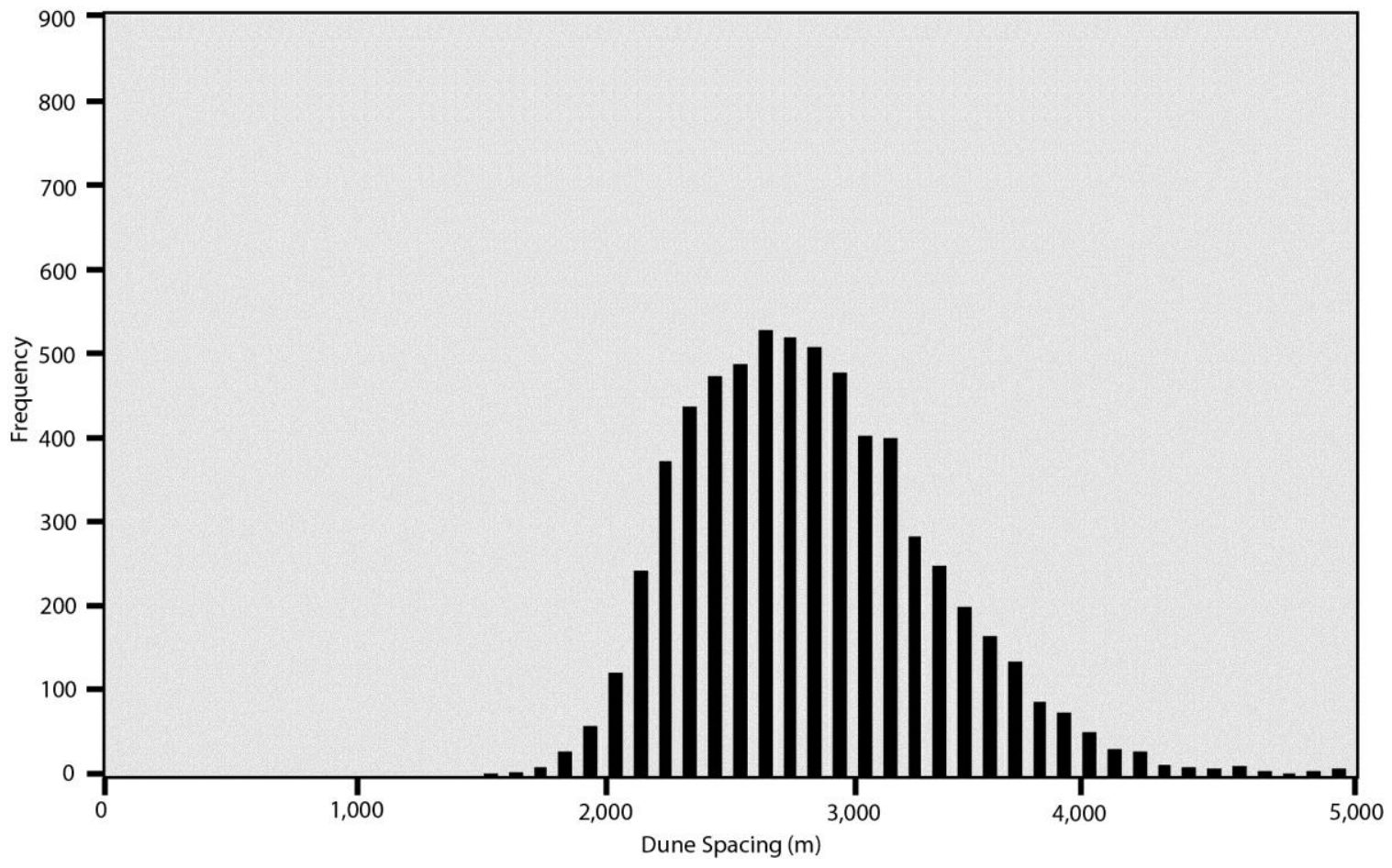


Fig. 16

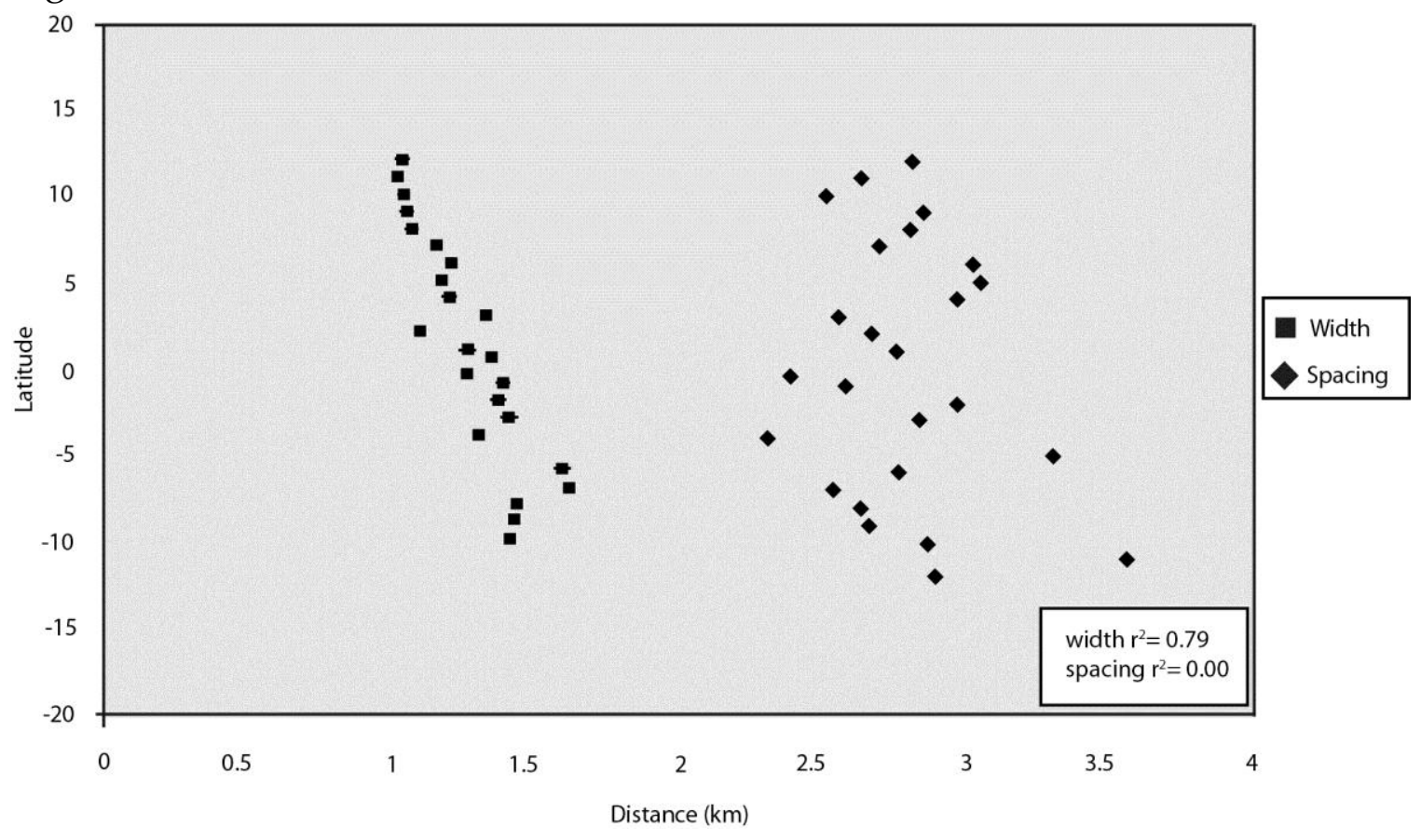


Fig. 17
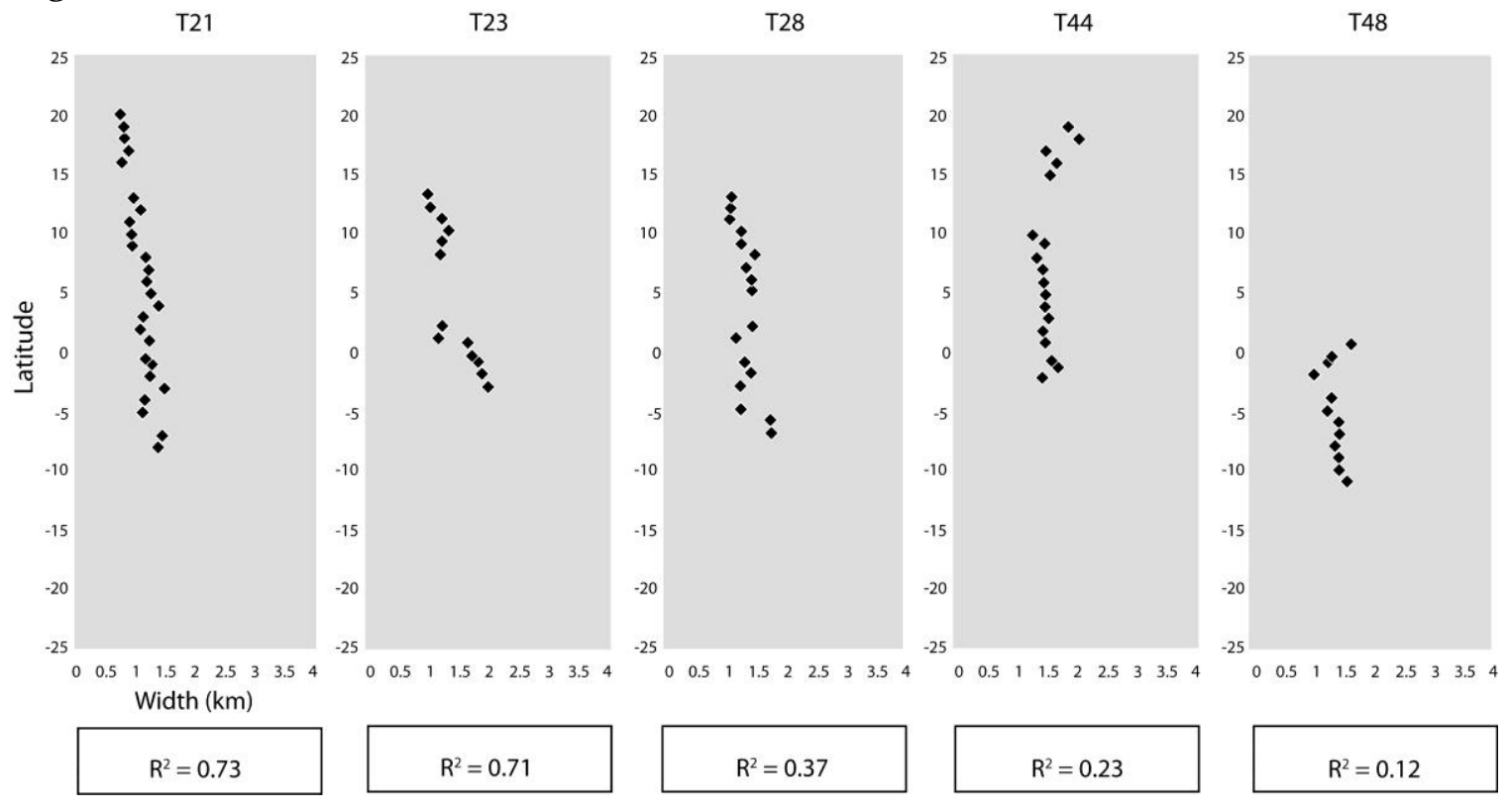
Fig. 18

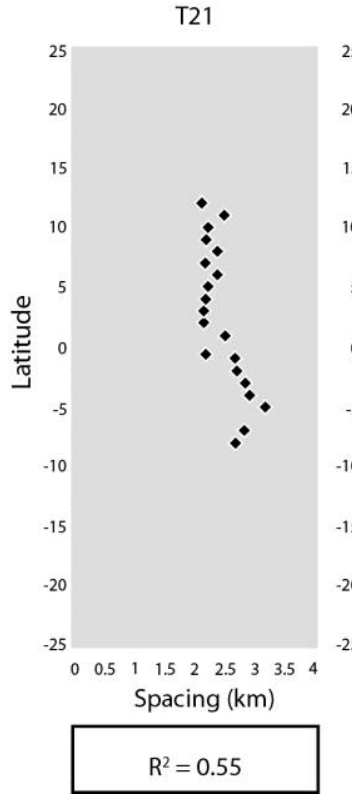

T23

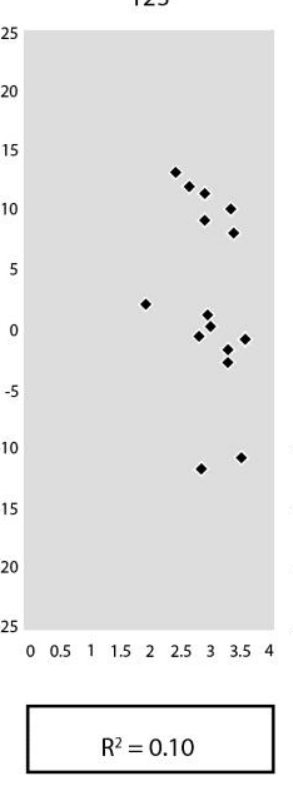

T28

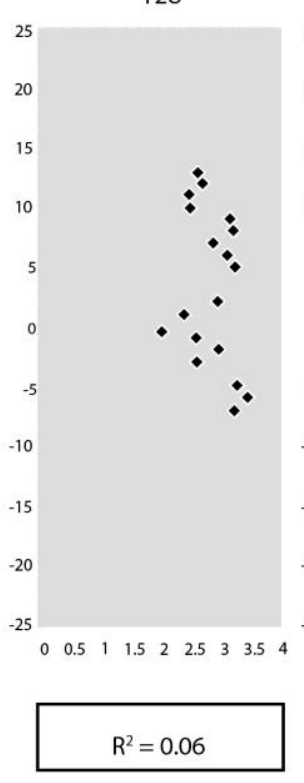

T44

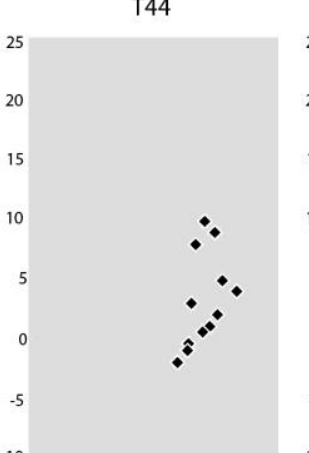

T48

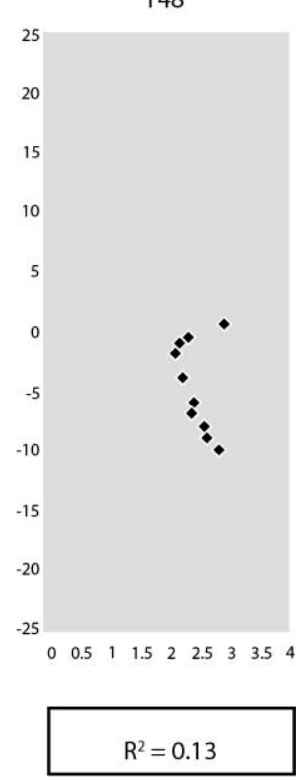


Fig. 19
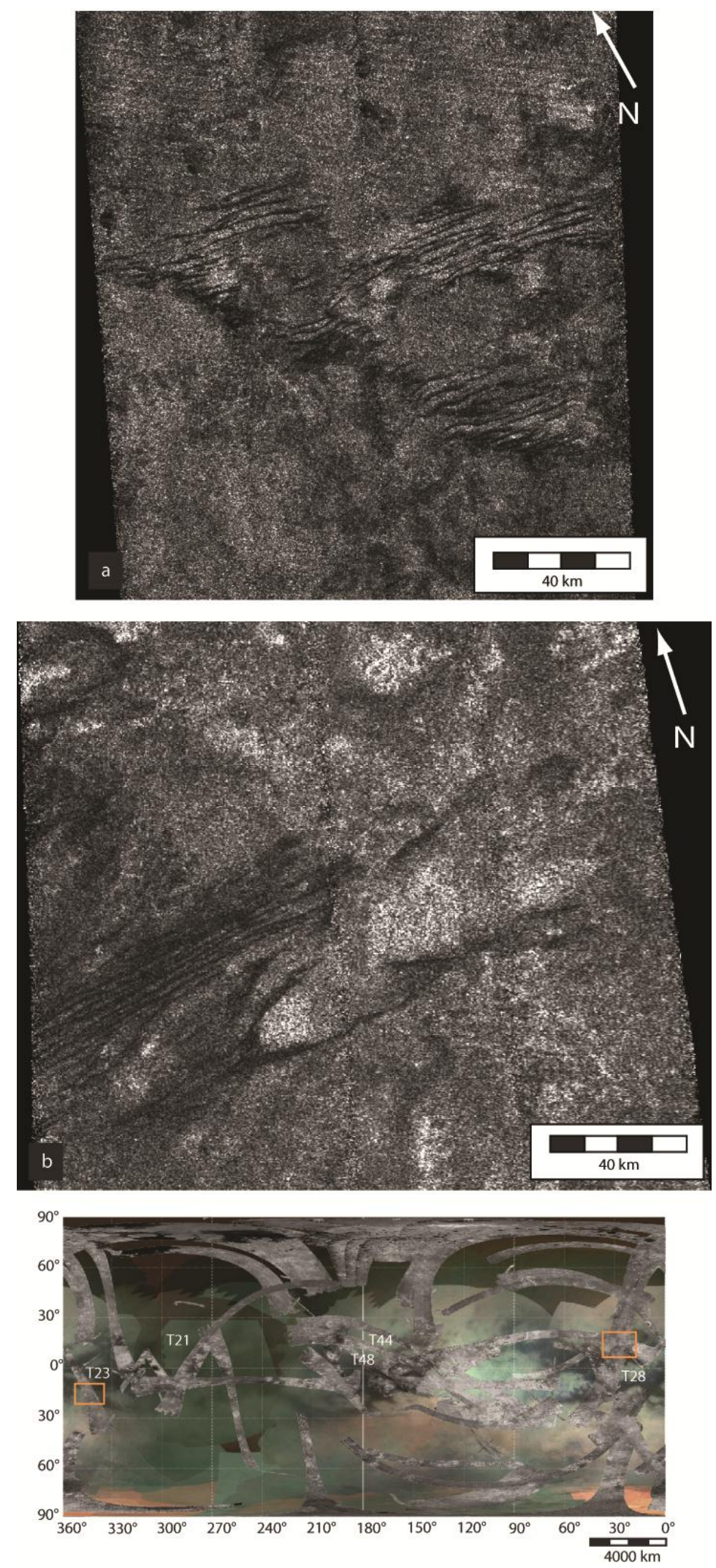
Fig. 20
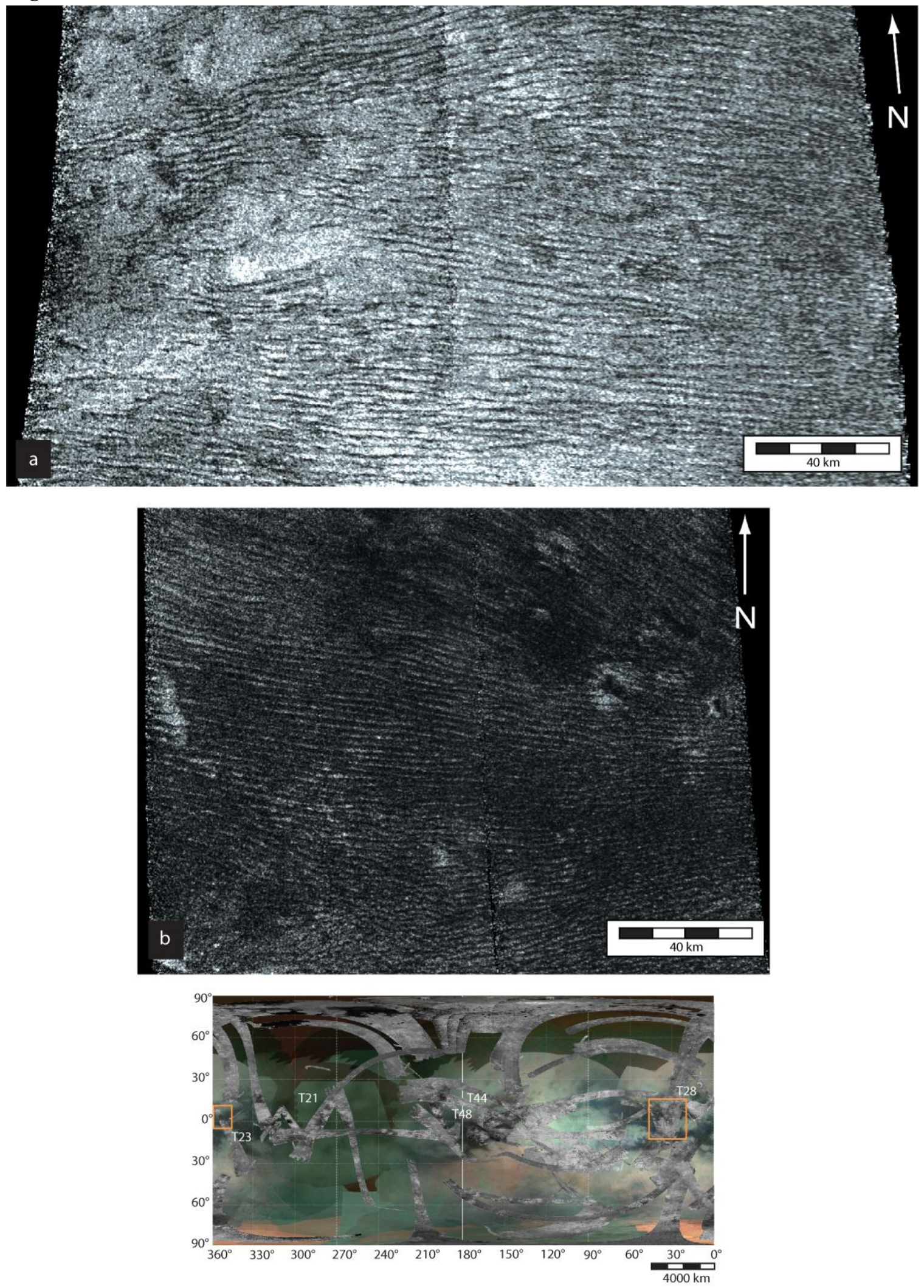
Fig. 21
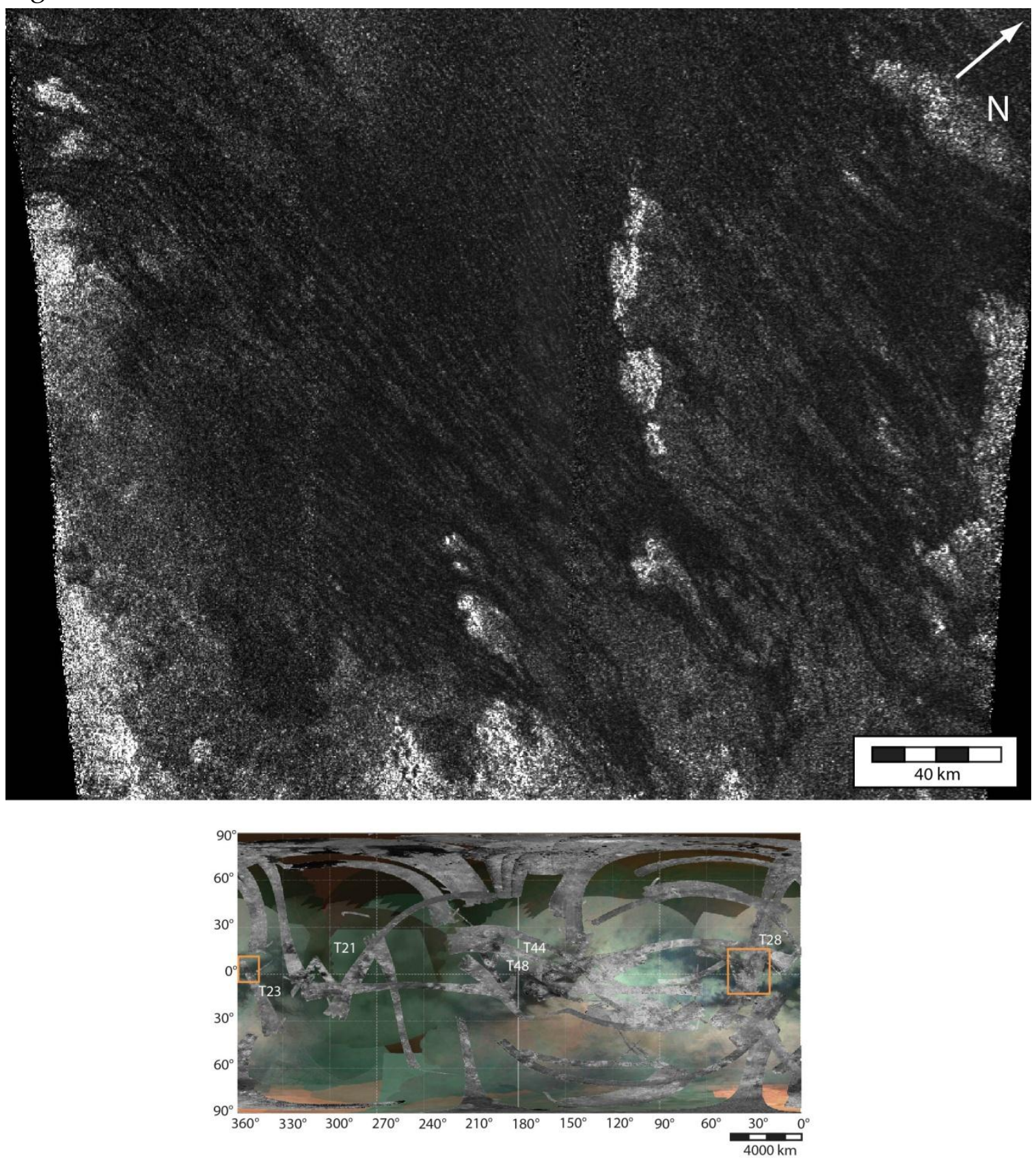
Fig. 22
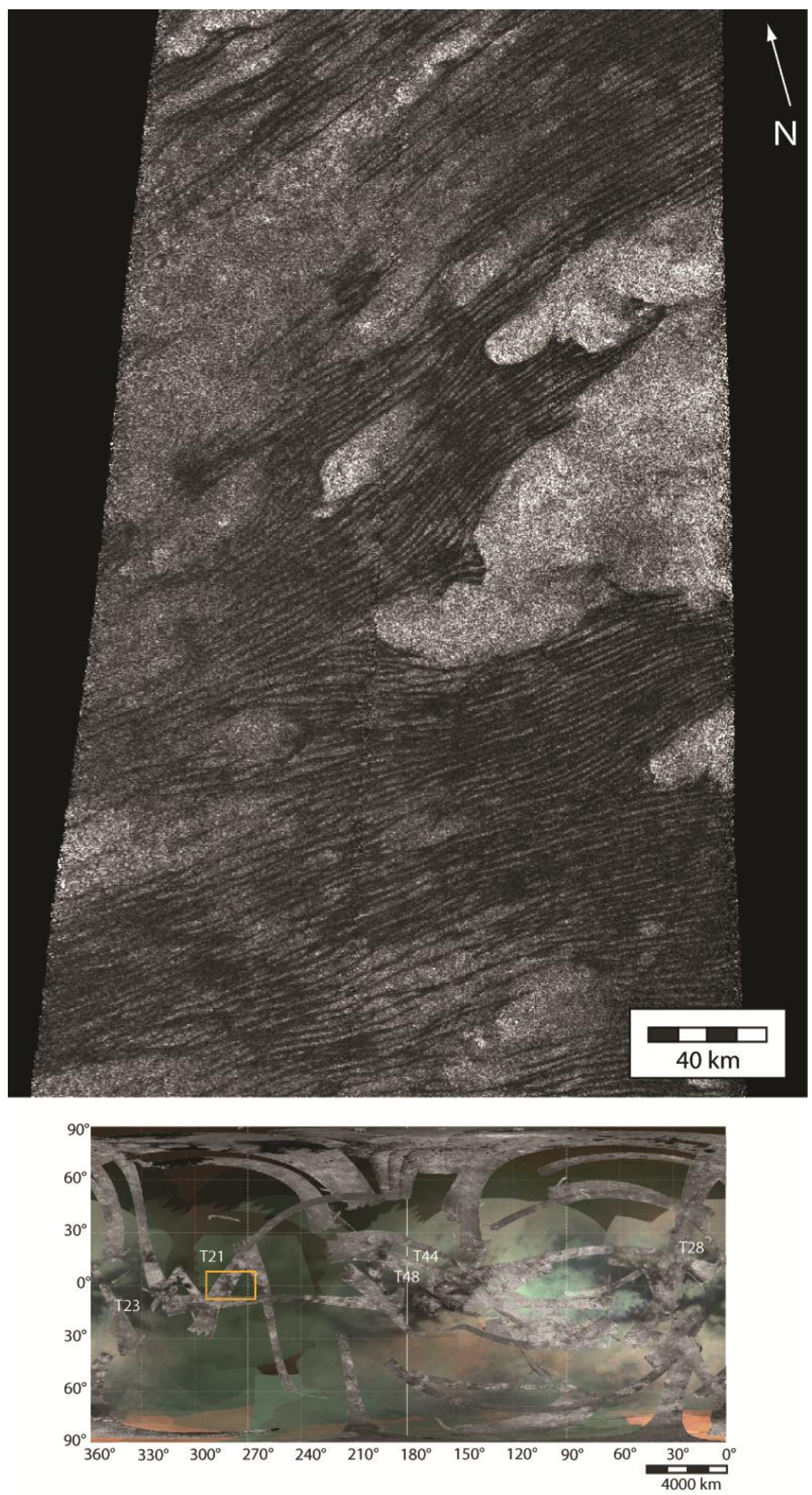
Fig. 23

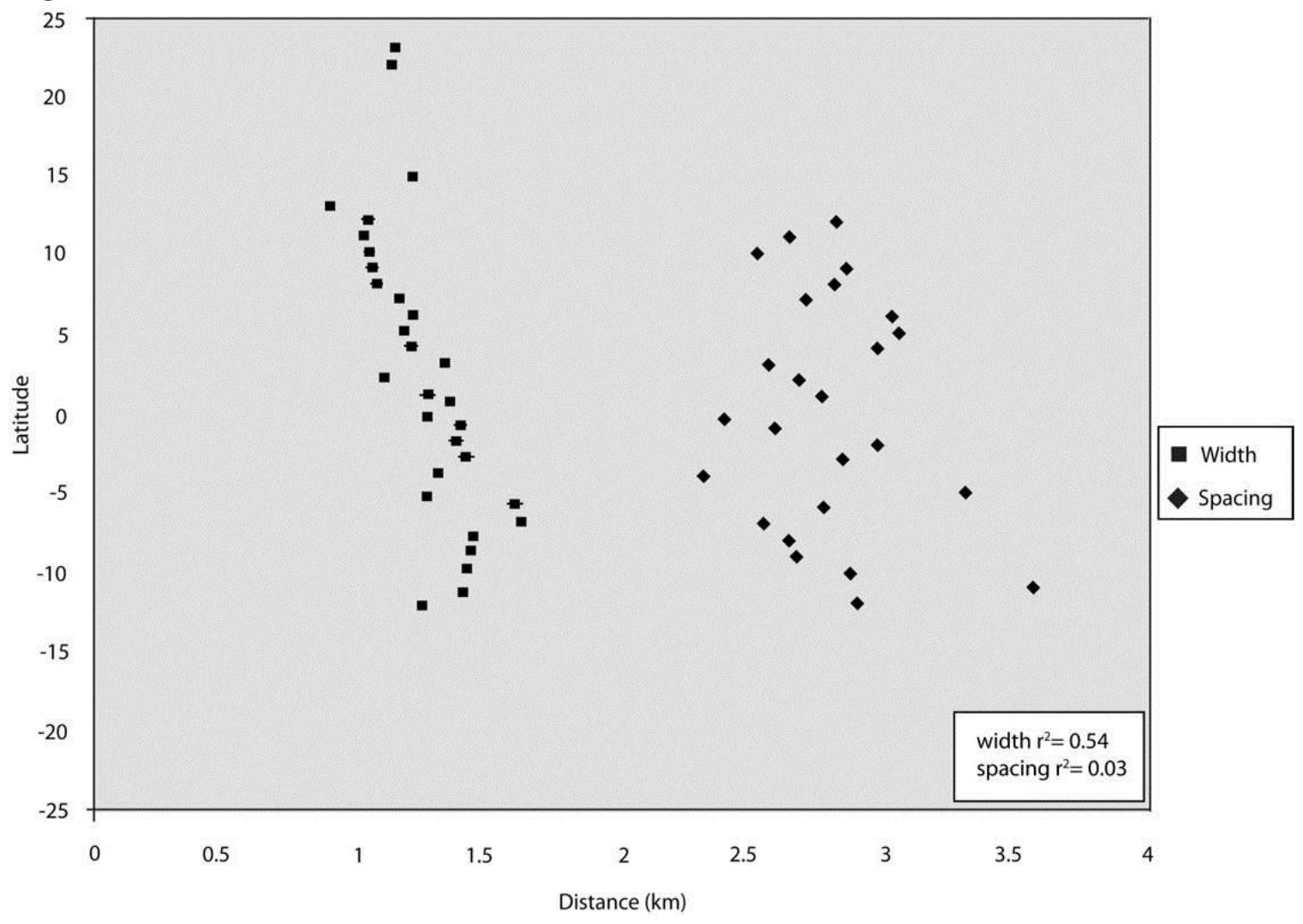


Fig. 24
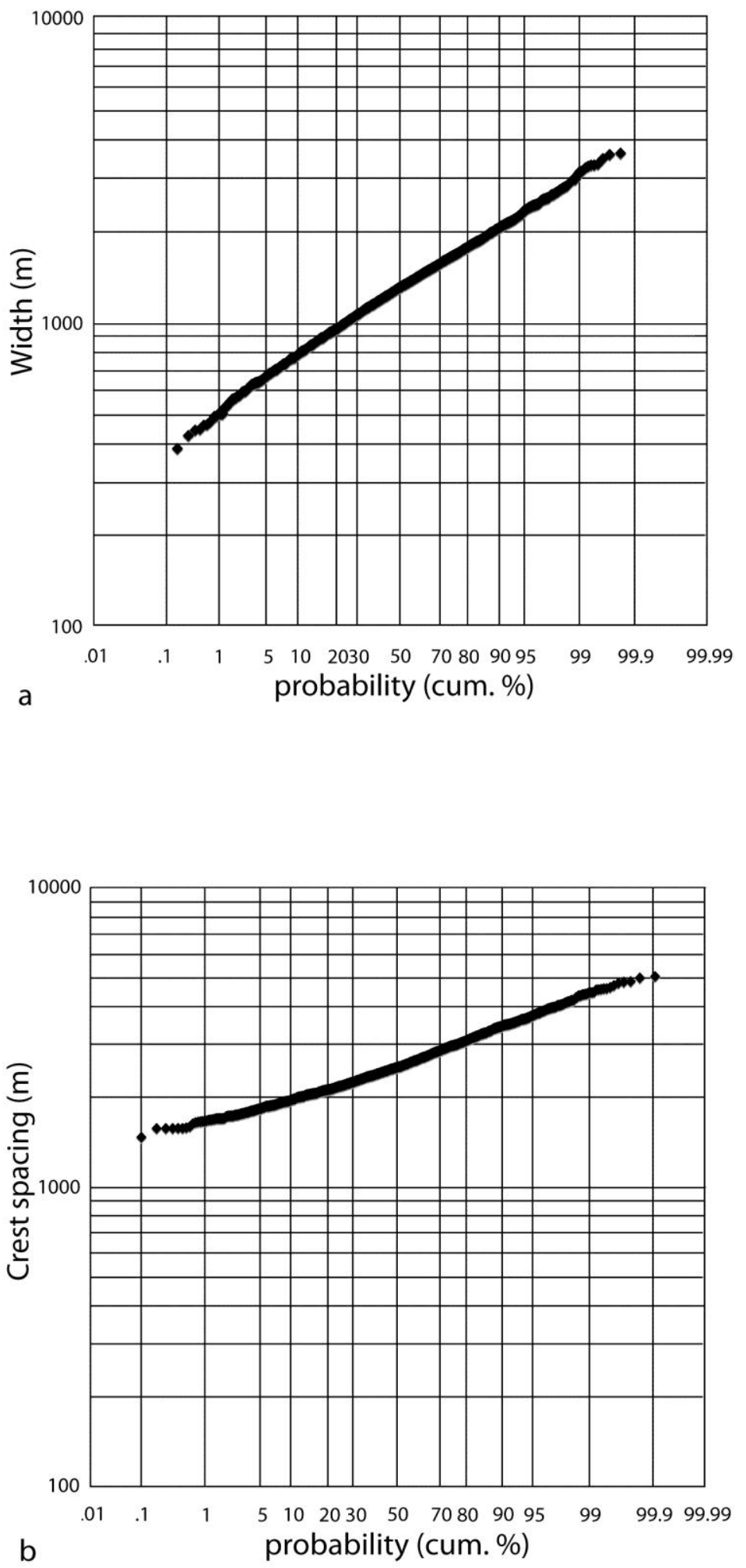
Fig. 25

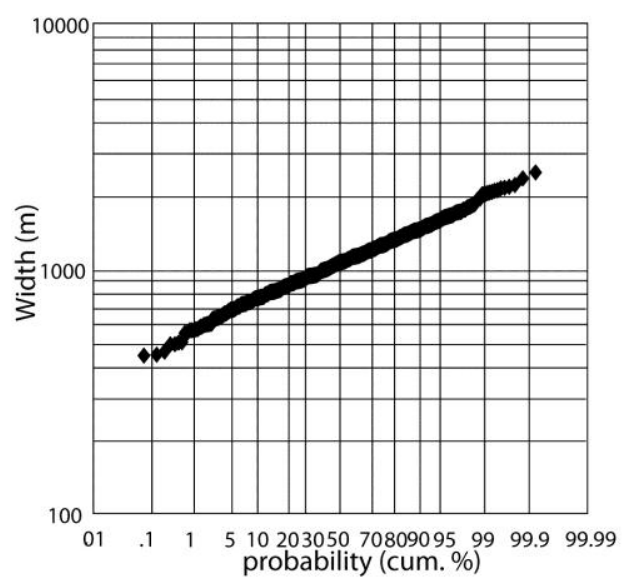

T28

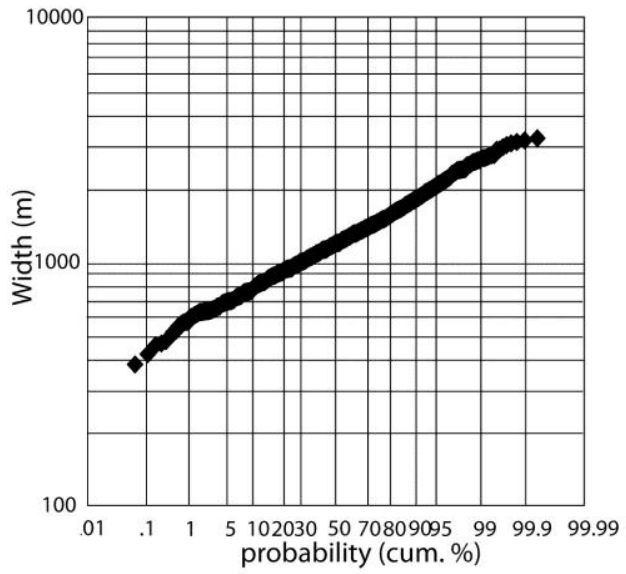

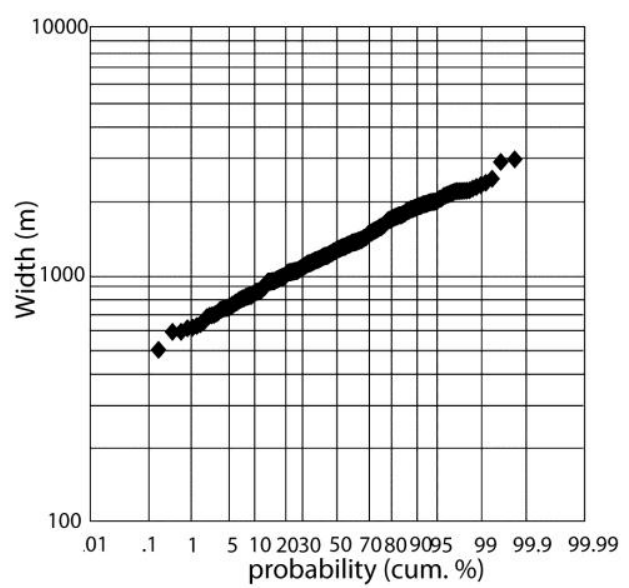

T48

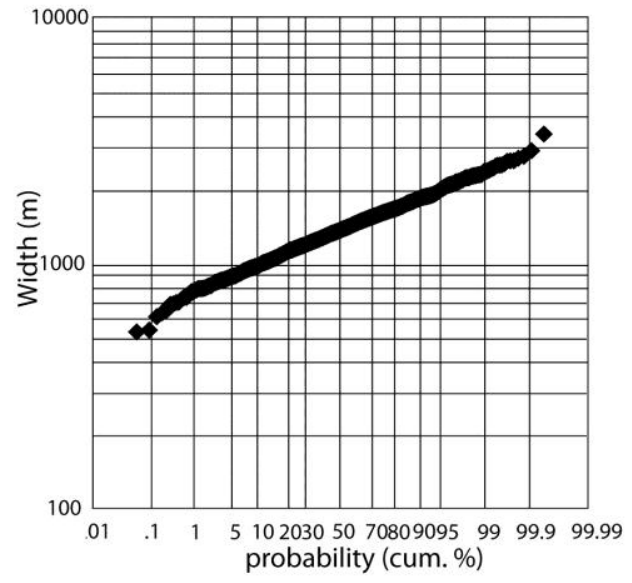

T44

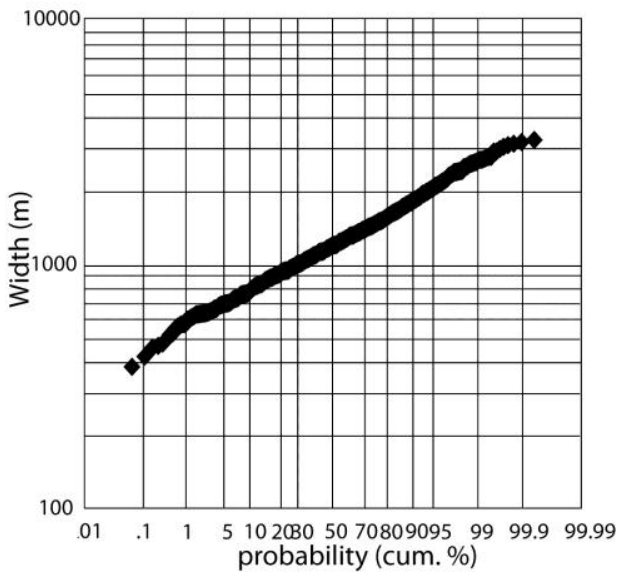


Fig. 26

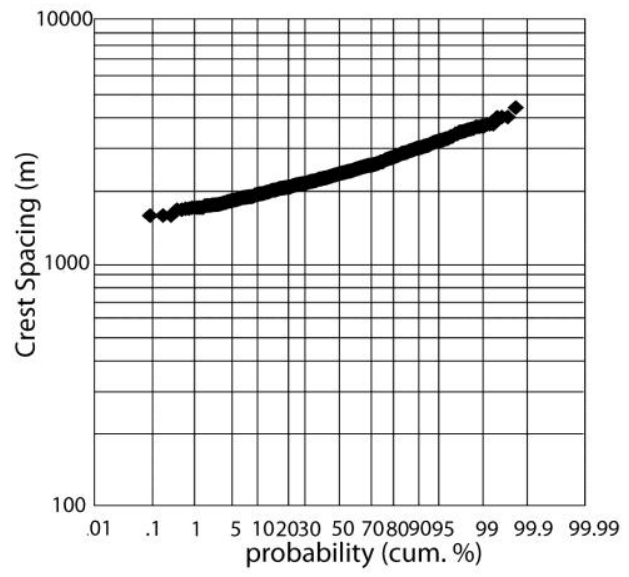

T28

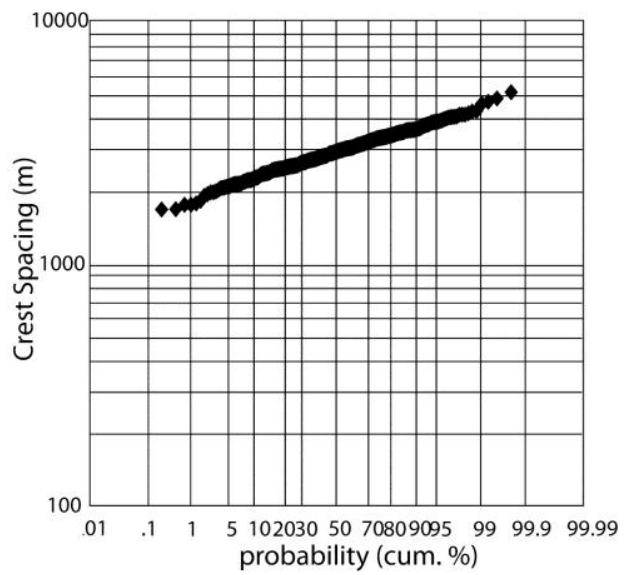

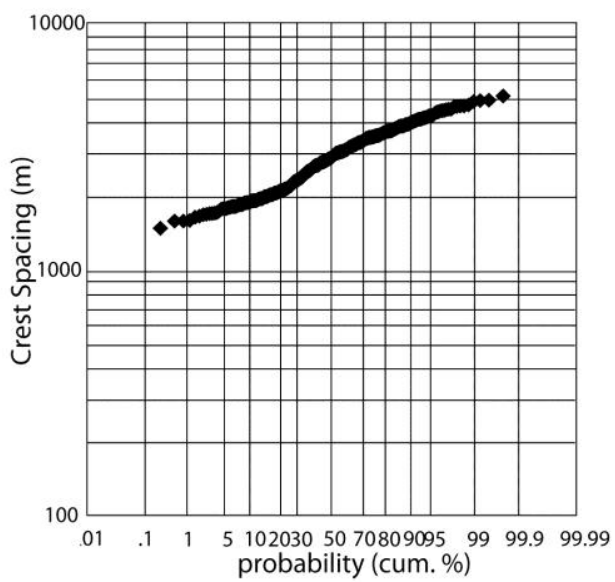

T48

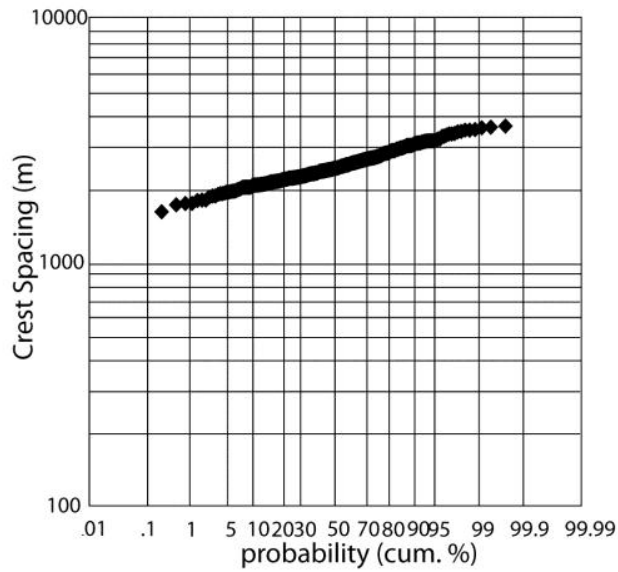

T44

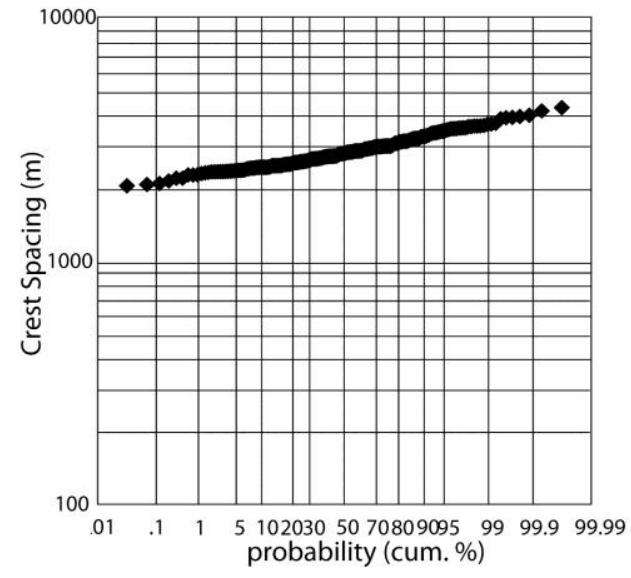


Fig. 27

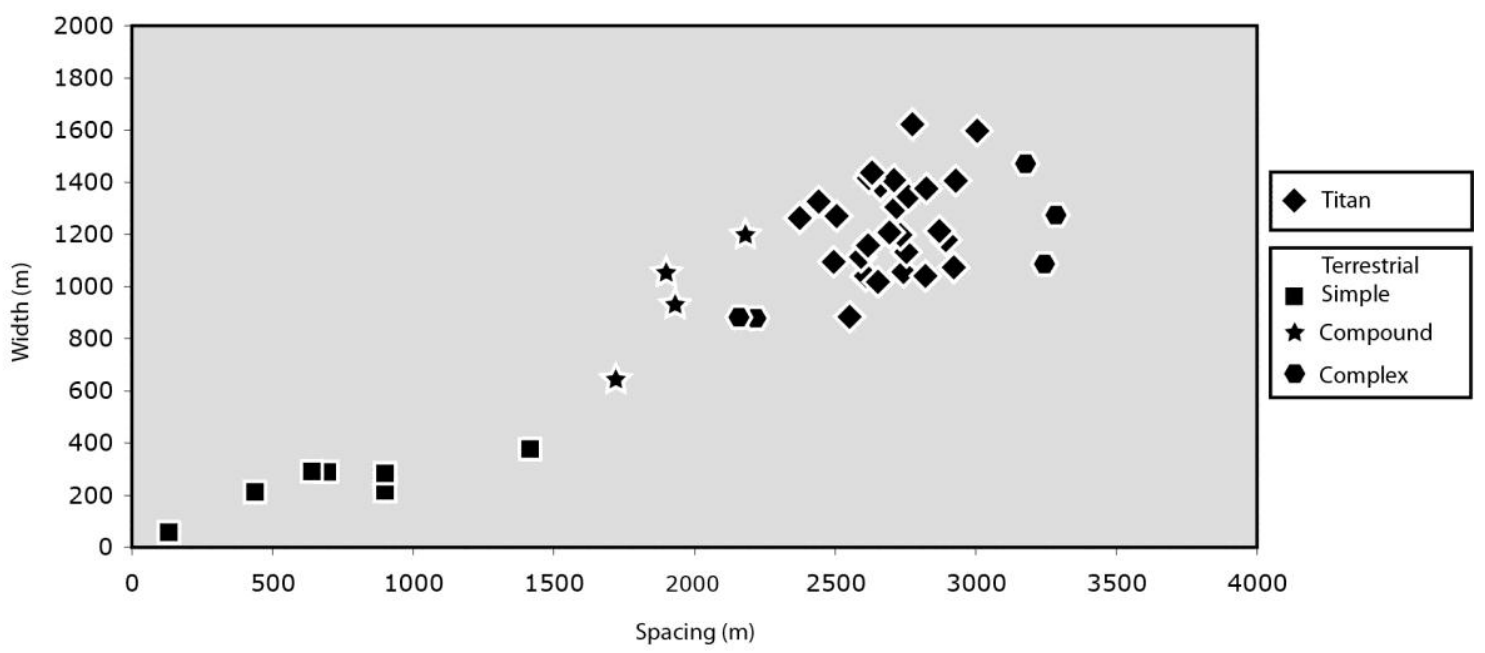




\section{Tables}

Table 1

All measured and calculated data. Represented in this table are data from all swaths combined and separated by

latitude.

\begin{tabular}{|c|c|c|c|c|c|c|c|c|c|c|c|c|c|c|c|c|c|c|}
\hline Lat. & Ave. Width & SD & SE & Min. & Max. & $n$ & Ave. ID & SD & SE & Min. & Max. & $n$ & Ave. spacing & SD & SE & Min. & Max. & $\mathrm{n}$ \\
\hline-10 & 1414 & 344 & 19 & 698 & 2618 & 312 & 1520 & 395 & 114 & 880 & 2020 & 12 & 2934 & 395 & 114 & 2290 & 3429 & 12 \\
\hline-8 & 1443 & 378 & 17 & 633 & 2630 & 487 & 1287 & 376 & 188 & 852 & 1727 & 4 & 2730 & 376 & 188 & 2192 & 3068 & 4 \\
\hline-7 & 1630 & 348 & 13 & 774 & 2961 & 686 & 1327 & 338 & 102 & 817 & 1722 & 11 & 2957 & 419 & 126 & 2231 & 3403 & 11 \\
\hline-6 & 1601 & 393 & 20 & 596 & 3200 & 399 & 1514 & 568 & 61 & 693 & 3033 & 87 & 3115 & 646 & 83 & 2102 & 4703 & 61 \\
\hline-5 & 1249 & 307 & 16 & 580 & 2277 & 362 & 2131 & 547 & 146 & 1616 & 3273 & 14 & 3380 & 549 & 147 & 2726 & 4472 & 14 \\
\hline-3 & 1415 & 355 & 28 & 780 & 2991 & 158 & 1324 & 345 & 51 & 576 & 2161 & 46 & 2739 & 361 & 61 & 2109 & 3632 & 35 \\
\hline-2 & 1381 & 372 & 20 & 678 & 3072 & 351 & 1392 & 449 & 32 & 569 & 3109 & 200 & 2773 & 584 & 41 & 1588 & 4399 & 200 \\
\hline-1 & 1394 & 346 & 17 & 715 & 2536 & 399 & 1270 & 515 & 40 & 522 & 3290 & 163 & 2664 & 623 & 49 & 1766 & 5042 & 163 \\
\hline-0.5 & 1267 & 347 & 27 & 635 & 2492 & 169 & 1063 & 241 & 21 & 580 & 1796 & 137 & 2330 & 310 & 26 & 1745 & 3421 & 137 \\
\hline 0.5 & 1353 & 376 & 25 & 436 & 2739 & 219 & 1342 & 287 & 22 & 616 & 2186 & 168 & 2695 & 343 & 26 & 1844 & 3563 & 168 \\
\hline 1 & 1275 & 440 & 26 & 290 & 3590 & 293 & 1204 & 379 & 25 & 475 & 2128 & 228 & 2479 & 439 & 32 & 1567 & 3616 & 194 \\
\hline 6 & 1219 & 476 & 16 & 291 & 3283 & 835 & 1464 & 447 & 44 & 746 & 2803 & 105 & 2683 & 501 & 49 & 1965 & 4180 & 105 \\
\hline 7 & 1165 & 449 & 18 & 363 & 3123 & 633 & 1283 & 413 & 39 & 635 & 2377 & 110 & 2448 & 458 & 44 & 1796 & 3667 & 110 \\
\hline 8 & 1078 & 402 & 18 & 361 & 2791 & 523 & 1669 & 585 & 51 & 832 & 3507 & 130 & 2747 & 679 & 63 & 1840 & 4790 & 117 \\
\hline 9 & 1062 & 408 & 17 & 218 & 3217 & 586 & 1555 & 550 & 47 & 721 & 3779 & 135 & 2617 & 638 & 55 & 1740 & 4988 & 133 \\
\hline 10 & 1044 & 354 & 17 & 291 & 2660 & 443 & 1529 & 544 & 51 & 633 & 3265 & 115 & 2573 & 657 & 62 & 1568 & 4571 & 111 \\
\hline 11 & 1022 & 260 & 16 & 437 & 1947 & 268 & 1624 & 541 & 45 & 0 & 3634 & 145 & 2646 & 548 & 46 & 1656 & 4830 & 144 \\
\hline 12 & 1045 & 260 & 22 & 566 & 1769 & 146 & 1772 & 534 & 62 & 608 & 2896 & 74 & 2817 & 544 & 63 & 1652 & 3982 & 74 \\
\hline 13 & 888 & 242 & 23 & 460 & 1837 & 111 & 1547 & 541 & 96 & 597 & 2965 & 32 & 2435 & 547 & 97 & 1576 & 4033 & 32 \\
\hline 15 & 1203 & 452 & 36 & 377 & 2680 & 157 & 1458 & 521 & 92 & 528 & 2643 & 32 & 2661 & 521 & 92 & 1647 & 3761 & 32 \\
\hline 22 & 1121 & 298 & 29 & 452 & 2129 & 103 & 1483 & 341 & 50 & 956 & 2684 & 46 & 2604 & 341 & 50 & 2077 & 3804 & 46 \\
\hline 23 & 1139 & 405 & 108 & 512 & 1697 & 14 & 1611 & 296 & 148 & 1300 & 1973 & 4 & 2750 & 296 & 148 & 2439 & 3112 & . \\
\hline
\end{tabular}


Table 2

Data from various terrestrial dunes (from Breed and Grow, 1979 and Lancaster, 1995) including mean dune widths and spacing and the spacing to width ratio.

\begin{tabular}{c|ccc} 
Type & Location & Spacing $(\mathrm{m})$ & Width $(\mathrm{m})$ \\
\hline \multirow{4}{*}{ Simple } & Great Sandy Desert (Australia) & 900 & 290 \\
& Kalahari Desert (southern Africa) & 700 & 290 \\
& Navajo Reservation (northern Arizona) & 150 & 43 \\
& NE Rub' al Khali (Saudi Arabia) & 1410 & 380 \\
& Simpson Desert (Australia) & 648 & 290 \\
& Simpson Desert (Australia) & 900 & 220 \\
\cline { 1 - 2 } Compound & SW Kalahari (southern Africa) & 435 & 220 \\
& Namib (SW Africa) & 1724 & 650 \\
& S Sahara (Niger) & 1900 & 1060 \\
& SW Rub' al Khali (Saudi Arabia) & 2180 & 1210 \\
& SW Sahara (Mauritania) & 1930 & 940 \\
& N Sahara (Algeria) & 3240 & 1090 \\
& Namib (SW Africa) & 2163 & 880 \\
& Namib (SW Africa) & 2200 & 880 \\
& Rub' al Khali (Saudi Arabia) & 3170 & 1480 \\
& S Sahara (Niger) & 3280 & 1280 \\
& W Rub' al Khali (Saudi Arabia) & 3170 & 1480
\end{tabular}

